\title{
Dead level contour technical design parameters required for sustainable crop production in semi- arid areas of Zimbabwe
}

Douglas Gumbo

Department of Soil Science and Environment, University of Zimbabwe

Menas Wuta ( $\triangle$ wokwawuta@yahoo.com )

Department of Soil Science and Environment, University of Zimbabwe https://orcid.org/0000-00025506-818X

Isaiah Nyagumbo

CIMMYT-Zimbabwe

\section{Research Article}

Keywords: DLC technology, maize yield, dry spells, optimum interval, rainwater harvesting

Posted Date: April 21st, 2021

DOl: https://doi.org/10.21203/rs.3.rs-428589/v1

License: (c) (i) This work is licensed under a Creative Commons Attribution 4.0 International License. Read Full License 


\section{Abstract}

Smallholder farmers in sub-Saharan Africa are increasingly exposed to risks such as erratic rainfall, prolonged dry spells, and frequent droughts that threaten sustainable crop production. This study assessed the effectiveness of dead level contours with innovations (DLC INN), dead level contours with infiltration pits (DLC INFIL), dead level contours with open channels (DLC OPEN) and standard graded contours (SGCs) in harvesting and storing water in the channel, improving crop conditions during the critical stages of maize growth on different soil textural groups in the Zvishavane District of Zimbabwe. The DLC INFIL, DLC OPEN and DLC INN outperformed the SGC under medium- and heavy-textured soils, with yields ranging between 1.7 and $2.36 \mathrm{t} /$ ha compared to $0.9 \mathrm{t} / \mathrm{ha}$ for the SGC. For light textured soils, the DLC INN had the highest maize yield, averaging $0.8 \mathrm{t} / \mathrm{ha}$. On heavy textured soils using DLC INN, DLC INFIL and DLC OPEN, smallholder farmers may use a spacing interval of 24-27 m. On medium textured soils, DLC INN and DLC INFIL can be used at a spacing interval of $18-21 \mathrm{~m}$ and 12 to $15 \mathrm{~m}$ with DLC OPEN. On light textured soils, farmers are advised to invest in DLC INN only, using a spacing interval of 12-15 m.

\section{Introduction}

Studies conducted in semi-arid regions of sub-Saharan Africa show that smallholder farmers are increasingly exposed to risks such as erratic rainfall, prolonged dry spells, and frequent droughts $[1,2,3$, 4, 5], making crop production unsustainable. In Zimbabwe, natural agro-ecological regions IV and $V$ are classified as semi-arid regions because they receive low and erratic rainfall below $500 \mathrm{~mm}$ per annum; therefore, sustainable crop production is difficult under rain-fed conditions [6, 7]. Despite the increased frequency of unpredictable seasonal changes and prolonged mid-season dry spells, most households in semi-arid regions are still dependent on rain-fed agriculture.

A dry spell is defined as a continuous period of no rainfall during a rainfall season lasting for 10 days or more [8]. Barron et al. [9] observed that prolonged dry spells contributed to low productivity in rain-fed agriculture because during such periods, crops suffer water stress that results in yield reduction or crop failure. Mupangwa et al. [5] studied dry spell occurrence in semi-arid areas and reported that meteorological dry spells of 21 days occurred in $70 \%$ of the seasons during the flowering stage of the maize crop. The flowering stage is critically important in the development of maize because it determines grain yield. In semi-arid zones, rain-fed maize yields are below $0.5 \mathrm{t} / \mathrm{h}$ for smallholder farmers with limited access to fertilizer [10] compared with $3.1 \mathrm{t} /$ ha for fields where infield rainwater harvesting and soil moisture conservation techniques have been applied [11]. With an estimated maize cropped area of 1 ha per household, this yield of $0.5 \mathrm{t} / \mathrm{ha}$ often falls far short of meeting average annual households' cereal requirements of at least $745 \mathrm{~kg}$ per annum [11].

Rockström and Barron [12] noted that farmers who are dependent on rainfed agriculture value every extra drop of water during a sensitive time of crop growth because it makes a significant difference to the survival of that crop. Molden et al., [13] and Nyagumbo et al., [14] recognie that the survival of a crop acts 
like a continuum from rainfed to fully irrigated agriculture. In semi-arid areas, the best way to grow crops is through irrigation but is limited due to increasing water scarcity, unreliable water bodies and prohibitive development costs [15]. There is therefore a need to explore farmer-derived in-field rainwater harvesting structures, such as the dead level contour (DLC), as potential sustainable crop production technologies for smallholder farmers who have very limited resources. The DLC is a farmer-derived infield rainwater harvesting technique that involves the construction of a zero gradient (dead level) contour channel that retains rather than disposes of water as a mitigatory measure to prolonged dry spells. This channel enhances the infield harvesting and infiltration of water rather than the drainage and removal of water from the field, as in the case of the standard graded contours [16].

DLC technology is a result of many modifications to the standard graded contour (SGC), which was introduced for use in smallholder farming areas in Zimbabwe in the 1930s and later enforced through the Natural Resources Act Sect. 52 in 1941 to promote soil and water conservation [17, 18]. The farmerderived in-field rainwater harvesting structures assessed in this study include the dead level contour with infiltration pits that are covered on top and rammed at the base (DLC INN), dead level contour with uncovered infiltration pits (DLC INFIL), and dead level contour without infiltration pits (DLC OPEN). Biazin et al., [19] observed that in situ and micro-catchment techniques can improve the soil water content of the rooting zone if properly constructed. Falkenmark \& Rockström, [20] observed that in semi-arid areas, 70$80 \%$ of rainfall can be made available to plants as soil moisture, but because of poorly designed technologies, the fraction of plant-available water can be as low as $40-50 \%$.

Except for a site-specific study conducted by [21], no other studies have investigated and documented the potential of farmer-derived infield rainwater harvesting structures and technologies that can minimize the impact of dry spells during the critical growth stage of a crop such as maize. Mupangwa et al. [21] suggested that the dead level contour enables poor lateral movement of soil water up to 3 metres from the channel. Mupangwa et al. [22] concluded that when using DLC technologies, soil moisture benefits derived from all labour, equipment and time invested in constructing these contours were short-term, unclear and not worth investing by smallholder farmers. This was contrary to farmers' observations in Chivi and Gwanda Districts of Zimbabwe, who, from experience, reported that when using infield rainwater harvesting structures, crops performed well within 15 metres from the structures, even when there were mid-season dry spells $[14,16,23,24]$. Given that the study by $[5,21,22]$ only covered four smallholder farms, one soil type and two growing seasons, the findings could be viewed as being inconclusive but do suggest caution.

There is therefore a need to consider the technical information on the design and layout of the DLC on different soil types since some farmers have limited access to technical information, which may result in the construction of inefficient systems in which farmers lose water from the field after harvesting it. There is also a knowledge gap related to the design parameters of the DLC, such as spacing of the contours and whether soils of different textures require the same spacing. It is therefore not clear how different technologies and farmer innovations perform on soils of different textures. This study thus assessed the effectiveness of each DLC technology in harvesting and storing water in the channel, improving crop 
conditions during the critical stage of maize growth and affecting maize yield on different soil textural groups in Zvishavane District of Zimbabwe. These three variables generated quantitative field evidence required to determine the optimum interval and technical specifications required for farmer-derived DLC technologies to mitigate the effects of dry spells and to ensure sustainable maize yields on different soil types.

\section{Methodology}

\section{General description of study site}

The study was conducted in Ward 16 (Fig. 1), the Mazvihwa communal area, a semi-arid area in the southern part of the Zvishavane district in Zimbabwe. Zvishavane District is in the south-central part of Zimbabwe. The study area falls in agroecological region $V$, receiving less than $500 \mathrm{~mm}$ per annum [6]. The rainfall regimes in Region $V$ are characterised by erratic patterns with frequent mid-season dry spells and early rainfall cut-offs that cause poor crop conditions or total crop failure, leaving farmers with very low yields or nothing to harvest. The southern part of Zvishavane District experiences severe food security crises due to recurring droughts [1]. The study area experiences high average monthly summer temperatures ranging between $31^{\circ}{ }^{\circ} \mathrm{C}$ and $38^{\circ} \mathrm{C}$, resulting in high potential evapotranspiration rates [25].

One of the main reasons why Ward 16 (Fig. 1) was selected was that all ten villages were involved in indigenous soil and water conservation (ISWC) in Africa Project from 1988 to 1993, which promoted a basket of options for farmer-derived in-field rainwater harvesting innovations [16].

There are ten villages in the Mutambi ward, each with $60-80$ households. Approximately $75 \%$ of the sampled farmers from each village on heavy textured soils had sandy clay loam, and $25 \%$ had sandy clay textures. The heavy textured soils were mainly derived from doleritic intrusions dominated by Colophospermum mopane, Combretum apiculatum and Acacia tree species. The farmers on medium textured soils had mainly sandy loam textures, and the sites were dominated by Sclerocarya birrea (marula) and Acacia tree species. Those on light textured soils had loamy sand and sand textures, with low percent clay. Vegetation on these soils is dominated by Julbernadia globiflora and Brachystegia species.

\section{Experimental plots}

This study was a randomised complete block design experiment with five replicates. There were fifteen (15) farmers in total, with five (5) farmers in each of the three soil textural groups (light, medium and heavy textured soils). The selection of farmers was based on the soil texture and location. Clay content was the main factor in defining the soil texture. All heavy textured soils had a clay content of more than $24 \%$, medium textured soils had a clay content of $10-24 \%$ and light textured soils had a clay content less than $10 \%$. The major soil types in the study area are shown in Table 1. 
Table 1

Soil types at experimental plots in Ward 16, Zvishavane District, Zimbabwe

\begin{tabular}{|lllll|}
\hline Soil texture (farmer classification) & Clay \% & Silt \% & Sand \% & Soil type \\
\hline Heavy textured soils & $>24$ & 10 & 60 & $\begin{array}{l}\text { Sandy clay, } \\
\text { Sandy clay loam }\end{array}$ \\
\hline Medium textured soils & $10-24$ & 6 & 65 & Sandy loam \\
\hline Light textured soils & $<10$ & $<5$ & 85 & Loamy sand \\
\hline
\end{tabular}

Each farmer represented a block or a replicate, thus giving a total of 5 replicates per soil textural group. Each selected farmer designated a $50 \mathrm{~m} \times 50 \mathrm{~m}$ plot for each selected technology in the same field but left an area of more than $30 \mathrm{~m}$ between plots to avoid overlap between the technologies. There were four treatments for each farmer: the dead level contour with innovations (DLC INN), dead level contour with infiltration pits (DLC INFIL), dead level contour with open channel (DLC OPEN) and the standard graded contour (SGC). Each treatment was represented once at each farm, thus giving four (4) plots per farmer.

A set of five farmers with the same soil texture who were within $500 \mathrm{~m}$ from each other formed a cluster. This was to ensure that all farmer sites were in areas with similar soils and experienced the same weather conditions. Figure 2 is a sketch diagram to illustrate the experimental layout at each farmer's plot. The depth and width of each channel were $0.75 \mathrm{~m}$ and $1.5 \mathrm{~m}$, respectively.

For the DLC INFIL, the base of the pits was compacted or rammed using soil from elsewhere (e.g., soil from termite mounds) to prevent deep percolation. Figure 3 shows a DLC with a covered top and rammed base. The infiltration pits had a temporary cover to reduce the loss of water through evaporation. A pit cover was constructed from wooden poles placed across the pit, which were then stabilized by placing Hessian bags and earth on top. The soil derived from excavating the channels and pits was used to make bunds along the downslope sides of the channels. The bunds were covered with natural (nonplanted) grasses during the rainy season, that stopped overtopping of excess water .

To minimize the effects of having different agronomic management practices, all fifteen farmers had the same experimental layout and were provided with the same inputs for three agricultural seasons. In each case, a standardized or recommended fertiliser regime in the area was applied to ensure that the crop had adequate nutrients to enable them to capitalise on available moisture. Tools (pick and shovel), rain gauge, seed (10 kg maize seed SC513) and top-dressing fertiliser (50 kg ammonium nitrate) were provided to each selected farmer. Farmers planted maize in the same week, and weeding was also performed during the same period.

\section{Data collection}

Rain gauges at each farm were installed at secure places to capture rainfall events and variability. Water levels in the channels were measured after each rainfall event using a metre ruler. The time water lasted in the channel for each technology was recorded for three agricultural seasons $(2011 / 12$ to $2013 / 14)$. 
Measurements were carried out at hourly intervals initially for the first three hours after a rainfall event followed by once every 24 hours until there was no water in the channel, as shown in Fig. 4a and 4b. Measurements were also recorded at $8 \mathrm{am}$ in the morning, where a rainfall event occurred during the night.

Farmer observation of crop conditions during flowering, silking and grain filling stages of the maize crop was performed for three agricultural seasons. The observations and experiences of farmers are important in improving the knowledge base in participatory agricultural research $[26,27]$. Farmers' observations of crop conditions during the critical stages of maize growth were included $[28,29,30,31]$ to understand the circumstances and factors under which farmers made their observations and to validate the research findings. A farmer-based qualitative scoring system for assessing crop condition was agreed upon by consensus as follows:

1. Excellent condition: Vigorous crop growth. No apparent visual sign of moisture stress, disease or nutrient deficiency

2. Good: Vigorous crop growth. No obvious visual sign of moisture stress or disease. Crop vigor may be limited slightly by nutrient deficiency

3. Moisture stressed: Crop performance limited by moisture stress associated with dry spells

4. Wilted crop: Crop performance severely limited by moisture stress and yield decline is obvious

The maize yield ( $\mathrm{t} / \mathrm{ha}$ ) in this study refers to crops harvested for dry grain only measured as kilograms per area of harvested land. Maize grain yields were determined at physiological maturity by manual harvesting of a subplot for each DLC technology at $3 \mathrm{~m}$ intervals starting from the technology channel. The subplots were divided into $3 \mathrm{~m}$ sections to make five subplots per technology per farmer. The first was $0 \mathrm{~m}$ to $3 \mathrm{~m}$, and the last was $12 \mathrm{~m}$ to $15 \mathrm{~m}$ from the technology channel. Maize cobs harvested were dried, threshed, used a testing protometer to measure grain moisture content of $12.5 \%$ and weighed separately for each subplot at the end of each agricultural season. This method of estimating grain yield has been used by [32, 33, 34]

\section{Data Analysis}

The data collected on mean maize yield and spacing of technologies were analysed using the Genstat 7.1 statistical package using analysis of variance. The least significant difference (LSD) at $P<0.05$ was used to differentiate between significantly different means [35].

\section{Results}

\section{Water storage in channels by dead level contour technologies}


The commencement of effective rains in the study area occurred in November for the three seasons (2011/12 to 2013/14). The highest daily rainfall events recorded at the farm sites were $31 \mathrm{~mm}, 27 \mathrm{~mm}$ and $29 \mathrm{~mm}$ in March and December for 2011/12, 2012/13 and 2013/14, respectively. The three seasons had total annual rainfall below $500 \mathrm{~mm}$ required for a maize crop to reach maturity. After rainfall events, water was collected into the channel of the dead level contour (DLC) technologies, and water levels were measured using a graduated dipstick or metre ruler. Depending on the site of the technology, the main sources of water to fill the channel were as follows:

- Direct rain drops into the DLC technology

- Run off from the cultivated fields or excess water from the upslope.

- Run off from outside the field

As shown in Table 2, the the dead level contour with innovations (DLC INN) stored water in the channel for longer periods than any other technology; however, it lasted longer (24 days) in heavy textured than in medium textured ( 21 days) and light textured soils (14 days). The DLC INN on heavy textured soils was the only technology that stored water in the channel until the end of the mid-season dry spells. Due to increased deep percolation water collected in the dead level contour with infiltration pits (DLC INFIL)and the dead level contour with open channel (DLC OPEN) lasted for less than one hour on light textured soils, while on medium to heavy textured soils, water lasted for approximately 18 days. The water in the standard graded contour (SGC) channel lasted for two (2) hours on medium- to heavy-textured soils. 
Table 2

Duration water lasting in channels for each technology at the study sites in Zvishavane District during the agricultural seasons from 2011/12 to 2013/14

\begin{tabular}{|c|c|c|c|c|c|}
\hline \multirow[t]{2}{*}{ Soil texture } & \multirow[t]{2}{*}{ Agricultural season } & \multicolumn{4}{|c|}{ Technology and Time (days) } \\
\hline & & DLC inno & DLC infil & DLC open & SGC \\
\hline \multirow[t]{4}{*}{ Light textured } & $2011 / 12$ & 12 & 0 & 0 & 0 \\
\hline & $2012 / 13$ & 14 & 0 & 0 & 0 \\
\hline & $2013 / 14$ & 16 & 0 & 0 & 0 \\
\hline & Seasonal Average & 14 & 0 & 0 & 0 \\
\hline \multirow[t]{4}{*}{ Medium textured } & $2011 / 12$ & 19 & 14 & 17 & 0 \\
\hline & $2012 / 13$ & 22 & 20 & 18 & 0 \\
\hline & $2013 / 14$ & 22 & 20 & 19 & 0 \\
\hline & Seasonal Average & 21 & 18 & 18 & 0 \\
\hline \multirow[t]{4}{*}{ Heavy textured } & $2011 / 12$ & 24 & 19 & 18 & 0 \\
\hline & $2012 / 13$ & 24 & 19 & 18 & 0 \\
\hline & $2013 / 14$ & 24 & 21 & 18 & 0 \\
\hline & Seasonal Average & 24 & 20 & 18 & 0 \\
\hline
\end{tabular}

During the flowering and silking stages, wilted crops were only observed in two seasons by farmers who employed DLC OPEN (60\%) and SGC (100\%) during the 2011/12 season.

Moisture-stressed crops were observed by farmers who employed DLC INFIL (20\%), DLC OPEN (60\%) and SGC (100\%) for all three seasons. Good crop conditions were observed by farmers who employed DLC INN (100\%) and DLC INFIL (80\%) during the first two agricultural seasons $(2011 / 12$ to $2012 / 13)$.

Excellent crop conditions were observed by $20 \%$ of the farmers using DLC INN, while good crop conditions were observed under DLC INN (100\%), DLC INFIL (80\%) and DLC OPEN (40\%) for the 2013/14 agricultural season.

The trend during the grain filling stage was different from that during the silking and flowering stages. Wilted crops were only observed by farmers who employed DLC OPEN (100\%) and SGC (100\%) during the first season (2011/12) and the 2012/13 to 2013/14 season SGC (40\%), as shown in Fig. 6a to 6c. During the grain filling stage, moisture-stressed crops were observed by farmers who employed DLC INN $(60 \%)$ and DLC INFIL (100\%) for the 2011/12 and 2012/13 seasons and SGC (60\%) for the 2013/14 season. 

2013/14 seasons, while good crop conditions were observed under DLC INN (60\%).

\section{Crop conditions in medium textured soils during flowering, silking and grain filling stages}

During the flowering and silking stages, wilted crops were only observed by farmers who used DLC OPEN (60\%) and SGC (100\%) during the first two seasons, as shown in Fig. 7a to 7c. Good crop conditions were observed by $80 \%$ using DLC INN and 100\% using DLC INFIL for all the three agricultural seasons.

During the grain filling stage, moisture-stressed crops were observed by farmers who employed DLC INFIL (100\%), DLC OPEN (60\%) and DLC INN (20\%) for all three seasons.

Good crop conditions during the grain filling stage were observed by $40 \%$ of the farmers using the DLC INN for the 2011/12 and 2013/14 seasons, as shown in Fig. 8a to 8c.

\section{Crop conditions in light textured soils during flowering, silking and grain filling stages}

During the flowering and silking stage, wilted crops were observed by farmers using the SGC $(100 \%$ DLC open (100\%).

As shown in Fig. 9a to 9c, good crop conditions were observed by $20-40 \%$ of the farmers using the DLC INN during the 2013/14 season, while moisture-stressed crops were observed under the DLC INFIL (100\%) and DLC INN (60-80\%).

During the grain filling stage, wilted crops were observed by farmers who used DLC OPEN (100\%), DLC INFIL (100\%) and SGC (100\%) during the first two seasons, as shown in Fig. 10a to 10c. Moisturestressed crops were observed by all (100\%) the farmers using the DLC INN during the 2011/12 and $2012 / 13$ agricultural seasons. Good crop conditions were only observed by $60 \%$ using DLC INN during the 2013/14 agricultural season.

\section{General observation of the effects of each technology on crop conditions}

\section{Wilting at silking, flowering and grain filling stages}

Wilted crops were observed on all soil types (100\% light and $80 \%$ medium and heavy textured) under SGC technology as well as under DLC INFIL (100\%) and DLC OPEN (100\%) on light textured soils (LTS). Farmers did not observe any crop wilting under the DLC INN employed on heavy (HTS)- and medium textured (MTS) soils. 
Moisture-stressed crops at the silking, flowering and grain filling stages

Moisture-stressed crops were common on heavy- and medium-textured soils where farmers employed DLC INFIL (60\%), DLC OPEN (80\%) and DLC INN (20\%).

\section{Good crop conditions at the silking, flowering and grain filling stages}

Positive (good crop condition at maturity) soil moisture conservation effects were observed on medium textured soils and heavy textured soils where farmers employed the DLC INN (60-80\%), DLC INFIL (80\%) and DLC OPEN (60\%).

\section{Excellent crop conditions at the silking, flowering and grain filling stages}

The DLC INN had excellent soil moisture conservation effects on heavy textured soils (20\%). No crops in excellent condition were observed under the DLC INFIL, DLC OPEN and SGC on all soil types.

\section{Waterlogging conditions}

Farmers also observed signs of water logging within the first three metres from the technology on all soil types, excellent and good crop conditions were observed from $3 \mathrm{~m}$ to $12 \mathrm{~m}$, and moisture-stressed crops were visible from $12 \mathrm{~m}-15 \mathrm{~m}$.

\section{Effect of technology on the mean maize yield of all soil types}

The mean yields obtained under the DLC INN were significantly different $(p<0.05)$ from yields obtained under DLC INFIL, DLC OPEN and SGC on all soil types; however, there were no significant differences between DLC INFIL and DLC OPEN on soil types, as shown in Table 3. Except in light textured soils, the mean yields under the DLC INN, DLC INFIL and DLC OPEN technologies were significantly different $(\mathrm{p}<$ 0.05) from those under the SGC technology. The mean maize yields above $1 \mathrm{t} /$ ha were obtained under the DLC INN, DLC INFIL and DLC OPEN on heavy ()- and medium-textured soils. The lowest mean maize yields were obtained under DLC INFIL, DLC OPEN and SGC technologies on light textured soils. 
Table 3

Means for maize yield under different technologies on all soil types for three agricultural seasons $(2011 / 12$ to 2013/14) in Zvishavane District. LSD = 0.140; S. E = Standard error, and the means for maize yield with the same letter were not significantly different.

\begin{tabular}{|lll|}
\hline Technology type & Soil type & Mean maize yield \pm S.E \\
\hline DLC INN & HTS & $1.740^{\mathrm{a}} \pm 0.05$ \\
\hline DLC INFIL & HTS & $1.500^{\mathrm{b}} \pm 0.05$ \\
\hline DLC OPEN & HTS & $1.440^{\mathrm{b}} \pm 0.05$ \\
\hline DLC INN & MTS & $1.360^{\mathrm{c}} \pm 0.05$ \\
\hline DLC OPEN & MTS & $1.020^{\mathrm{d}} \pm 0.05$ \\
\hline DLC INFIL & MTS & $1.000^{\mathrm{d}} \pm 0.05$ \\
\hline DLC INN & LTS & $0.700^{\mathrm{e}} \pm 0.05$ \\
\hline SGC & HTS & $0.640^{\mathrm{e}} \pm 0.05$ \\
\hline SGC & MTS & $0.390^{\mathrm{f}} \pm 0.05$ \\
\hline DLC INFIL & LTS & $0.240^{\mathrm{g}} \pm 0.05$ \\
\hline DLC OPEN & LTS & $0.190^{\mathrm{g}} \pm 0.05$ \\
\hline SGC & LTS & $0.130^{\mathrm{g}} \pm 0.05$ \\
\hline
\end{tabular}

\section{The effects of DLC technologies on maize yield in heavy textured soils by distance}

The mean yields obtained under the DLC INN were not significantly different $(p>0.05)$ from yields obtained under DLC INFIL and DLC OPEN between $3 \mathrm{~m}$ and $12 \mathrm{~m}$ distances from the technology channel; however, there were significant differences at 0-3 m and $15 \mathrm{~m}$. As shown in Fig. 11a to 11c, the mean yields under the three DLC technologies were significantly different $(p<0.05)$ from the SGC technology. The highest mean maize yields for the three DLC technologies (DLC INN 2.36 t/ha. DLC INFIL $2.24 \mathrm{t} / \mathrm{ha}$ and DLC OPEN $1.7 \mathrm{t} / \mathrm{ha}$ ) were obtained between $6 \mathrm{~m}$ and $9 \mathrm{~m}$ from the channel, while that for SGC was $0.9 \mathrm{t} / \mathrm{ha}$. The lowest maize yields, however, were recorded between $12 \mathrm{~m}$ and $15 \mathrm{~m}$ (DLC INN $0.8 \mathrm{t} / \mathrm{ha}$. DLC INFIL 0.57 t/ha, DLC OPEN 0.5 t/ha and SGC 0.3 t/ha). The DLC INN, DLC INFIL and DLC OPEN technologies performed better than the SGC for every distance from the technology channel. The SGC had the lowest mean yield at every distance from the technology. The yield was observed to be lower within $3 \mathrm{~m}$ and between $12 \mathrm{~m}$ and $15 \mathrm{~m}$ from the technology channel for all DLC technologies employed on all soil textural groups due to waterlogging and moisture stress, respectively. 
Since average yields started going down at $12 \mathrm{~m}$ from the technology channel, farmers employing the DLC INN, DLC INFIL and DLC OPEN are advised to use an optimum spacing of $24 \mathrm{~m}(12 \mathrm{~m} \times 2)$ between

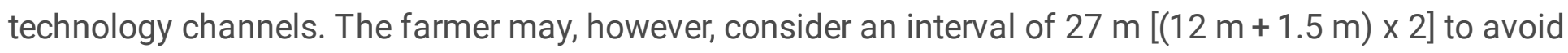
waterlogging likely to be caused by overlap. For SGC, average yields diminish at $6 \mathrm{~m}$ from the technology

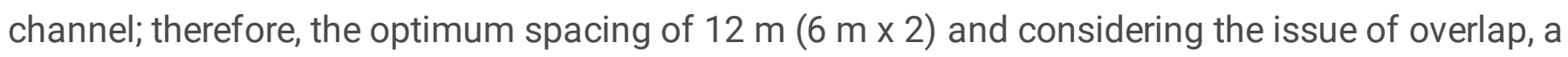
spacing interval of $15 \mathrm{~m}[(6 \mathrm{~m}+1.5 \mathrm{~m}) \times 2]$ will be recommended. Figure 12 is an illustration showing the layout and spacing for the DLC technologies on heavy textured soils.

\section{The effects of DLC technologies on maize yield in medium- textured soils}

There were significant differences $(p<0.05)$ in mean maize yield between DLC INN and the other three technologies (DLC INFIL, DLC OPEN and SGC), as shown in Fig. 13a to 13c. There was, however, no significant difference $(p>0.05)$ in mean maize yield between DLC INFIL and DLC open on medium textured soils. The mean yields for DLC INFIL and DLC OPEN were significantly different from the yields obtained under SGC.

Since average yields obtained from the DLC INN and DLC INFIL were not significantly different $(p>0.05)$ and started going down to below $1.5 \mathrm{t} / \mathrm{ha}$ at $9 \mathrm{~m}$ from the technology channel, farmers employing these technologies on medium textured soils are advised to use an optimum spacing of $18 \mathrm{~m}(9 \mathrm{~m} \times 2)$. The farmer may, however, consider an interval of $21 \mathrm{~m}[(9 \mathrm{~m}+1.5 \mathrm{~m}) \times 2]$ to avoid waterlogging due to overlap. For DLC, open average yields diminish at $6 \mathrm{~m}$ from the technology channel; therefore, the optimum spacing of $12 \mathrm{~m}(6 \mathrm{~m} \times 2)$ and considering the issue of overlap, a spacing interval of $15 \mathrm{~m} \mathrm{[}(6$ $m+1.5 \mathrm{~m}) \times 2$ ] will be recommended. For the SGC, the average maize yield was very low even at $3 \mathrm{~m}$ from the technology channel, and it would not be practical to employ the SGC as an infield rainwater harvesting technology but rather for soil conservation purposes.

\section{The effects of DLC technologies on maize yield in light- textured soils}

The maize yield obtained under DLC INN was significantly different $(p<0.05)$ from that obtained under SGC, DLC INFIL and DLC OPEN technologies at $3 \mathrm{~m}$ to $9 \mathrm{~m}$ from the technology channel. There was no significant difference ( $p>0.05)$ between DLC infil, DLC open and SGC on light textured soils. The SGC, DLC infil and DLC open had the lowest mean yield at every distance from the technology, as shown 14 a to 14c. The DLC inno had mean yields of $0.8 \mathrm{t} / \mathrm{ha}$, while the other three technologies there were below 0.2 $t /$ ha or there were no harvests at all due to total crop failure. The optimum spacing of $12 \mathrm{~m}(6 \mathrm{~m} \times 2)$ and considering the issue of overlap, a spacing interval of $15 \mathrm{~m}[(6 \mathrm{~m}+1.5 \mathrm{~m}) \times 2]$ will be recommended.

\section{Discussion}

\section{Water storage}


For all the soil types, the period during which water was stored in a channel was dependent on the type of technology employed and the soil type. The dead level contour with innovation (DLC INN), dead level contour with open channel (DLC OPEN) and dead level contour with infiltration pits (DLC INFIL) on heavyand medium-textured soils stored water in the channel for longer periods than the standard graded contour (SGC) on all soil types. The DLC INN on heavy textured soils was the only technology that stored water in the channel until the end of the mid-season dry spells. This observation concurs with [36], who observed that water harvesting can contribute to water availability during dry spells.

While water harvesting technologies help in moisture retention, not all retained water is available for plant use, as some of it is lost to evaporation, infiltration and/or deep percolation [37]. This study also noted that technological design and layout played a significant role in moisture retention. The effectiveness of most rainwater harvesting technologies in capturing and storing water is influenced by the type of technology, its layout and the distance from the harvesting structure [38]. Mutekwa \& Kusangaya, [39] also noted that technologies such as the DLC INN, although they are relatively new in Zimbabwe, can harvest, store and reduce evaporation because of a zero gradient when employed on soils with good water holding capacity. This can address the effects of a dry spell and contribute to improved crop yields.

\section{Observations of crop conditions during critical stages of maize growth}

In medium- to heavy-textured soils, the crop conditions during flowering ranged from good to excellent for all DLC technologies except SGC. Crop conditions were, however, lower within the $3 \mathrm{~m}$ distance from the technology channel, both upslope and down, as a result of waterlogging. This is similar to observations made by Ren et al. [40] that maize thrives on well-drained soils and waterlogging should be avoided during the flowering and yield formation periods. In this study, the performance of the DLC technologies was better at a distance between $3 \mathrm{~m}$ and $12 \mathrm{~m}$ from the technology on medium- and heavy-textured soils than on light-textured soils. This was largely because of the combination of better drainage than that within $3 \mathrm{~m}$ from the technology channel, where temporary waterlogging reduced crop growth.

In the semi-arid areas of Zimbabwe, the effect of waterlogging has been found to be pronounced under the planting basin tillage system, where water tends to stagnate in the plots after heavy thunderstorms during the early part of the season [36, 41, 42]. Mazvimavi and Twomlow [43] reported that exposing young maize plants to 24 hours of water-logged conditions resulted in a yield reduction of $37.6 \%$ compared with a crop that was never waterlogged. Reduced crop yields due to waterlogging have also been reported by Griffith et al. [44] when conservation agriculture technologies such as basins were employed on poorly drained soils. Areas that experience waterlogging, especially within $3 \mathrm{~m}$ both upslope and downslope, require crop switching. There is a need to identify crops that are tolerant to waterlogging that can be planted within $3 \mathrm{~m}$ from the technology channel.

\section{Maize yield}


Furthermore, the Intergovernmental Panel on Climate Change (IPCC) report [45] predicted that global warming is most likely to increase water scarcity in semi-arid areas, which may result in very low yields for rain-fed agriculture. The results of this study showed that not all DLC technologies improve the maize

grain yield in all soil types under prolonged dry spell conditions. This study has generated new knowledge on technical design parameters such as spacing, layout and matching DLC technology with soil textural groups. Considering these design parameters can ensure sustainable maize production when farmers are faced with prolonged dry spells due to climate change. A farmer whose field has heavy textured soils can make an informed technological choice. The DLC INN, DLC INFIL and DLC OPEN had better grain yields in heavy- to medium-textured soils compared to standard graded contours. The better yields obtained from DLC technologies employed on heavy and medium textured soils match the findings on soil moisture content assessment in this study, which established that a mid-season dry spell can be addressed by employing technologies that can effectively harvest, reduce evaporation, retain and store water that benefits a maize crop.

These results concur with Mugabe [46] and Mupangwa et al. [36], who observed that infield water harvesting can contribute to water availability, which can later enhance crop establishment and survival during dry spells. The moisture conservation effect of the DLC technologies and the distance from the technology channel are important variables in determining crop yield and optimum spacing interval of each technology on different soil types. The horizontal spacing interval for each of the DLC technologies has remained at the farmer's discretion. In the early days of enforced establishment of SGC, there was an unwritten rule that the size was adequate if the car, driven by the District Commissioner through the field, could fit in the standard contour channel [47]. A rule of thumb for the spacing of contour lines was $20 \mathrm{~m}$ to $30 \mathrm{~m}$ for gentle slopes (gradient: less than 5 percent) and 10 to $15 \mathrm{~m}$ for steeper slopes (gradient: more than 10 percent [48].

The rule of thumb should be that the spacing for each DLC technology should match the soil textural group.

\section{Conclusion}

This study generated new knowledge on the dead level contour (DLC) technical design parameters required for sustainable maize production in semi-arid areas of Zimbabwe. When DLC technologies are correctly matched to soil type with the correct horizontal interval, they can address the effects of midseason dry spells, as evidenced by better water retention in channels, enhanced soil moisture and improved yields. The moisture conservation effect of the DLC technologies and the distance from the technology channel are important variables in determining crop yield and optimum spacing interval of each technology on different soil types.

Based on the duration water was stored in the technology channel, conditions of crops observed by farmers during critical stages of maize growth and average maize yields obtained under each technology 
employed in this study, smallholder farmers in semi-arid areas of Zimbabwe can use the following DLC design recommendations for different soil textural groups on average slopes of $2 \%$ :

1. On heavy textured soils, smallholder farmers may invest in dead level contour with innovations (DLC INN) or dead level contour with infiltration pits (DLC INFIL) or dead level contour with open channel (DLC OPEN) using a spacing interval of 24-27 $\mathrm{m}$ with the potential to obtain average yields as high as DLC INN $2.36 \mathrm{t} / \mathrm{ha}$. DLC INFIL $2.24 \mathrm{t} / \mathrm{ha}$ and DLC OPEN $1.7 \mathrm{t} / \mathrm{ha}$.

2. In medium textured soils, DLC INN and DLC INFIL can be used at a spacing interval of 18-21 $\mathrm{m}$ with the potential to obtain average yields of $1.7 \mathrm{t} / \mathrm{ha}$. A DLC OPEN can also be employed at spacing intervals of $12-15 \mathrm{~m}$ with the potential to obtain $1.4 \mathrm{t} / \mathrm{ha}$

3. In light textured soils, farmers are advised to invest in DLC INN only using spacing intervals of 12-15 $\mathrm{m}$ with the potential to obtain $0.8 \mathrm{t} / \mathrm{ha}$ under prolonged dry spells.

Further studies are, however, required to determine the effect of overlap of adjacent DLC structures on spacing and design adjustments required for different slopes.

\section{Declarations}

\section{Data availability statement}

The datasets generated and/or analysed during the current study are available from the corresponding author on reasonable request.

Authors' contributions: All authors have made substantial contributions and have agreed with the content of the manuscript.

Funding: The research leading to these results received funding from DEMEX Consulting under Grant Agreement Number PhD 02/2012.

Conflict of interest: No potential conflicts of interest were reported by the authors.

Declaration: The people who appear in the figures consented to participate in the research and granted us permission to publish their images.

\section{References}

1. Bird K, Shepherd A. Livelihoods and Chronic Poverty in Semi-Arid Zimbabwe. World Development. 2003; 31(3):591-610.

2. Kahinda J, Rockström J, Taigbenu AE, Dimes J. Rainwater harvesting to enhance water productivity of rainfed agriculture in the semi-arid Zimbabwe. Physics and Chemistry of the Earth. 2007; https://doi.org/10.1016/j.pce.2007.07.011 
3. Makurira H. Water Productivity in Rainfed Agriculture: Redrawing the Rainbow of Water to Achieve Food security in Rainfed Smallholder system. Ph.D. diss. Delft University of Technology, 2010.

4. Motsi KE, Chuma E, Mukamuri B. Rainwater harvesting for sustainable agriculture in communal lands of Zimbabwe. Physics and Chemistry of the Earth. 2004; https://doi.org/10.1016/j.pce.2004.08.008

5. Mupangwa W, Walker S, Twomlow S. Start, end and dry spells of the growing season in semi-arid southern Zimbabwe. Journal of Arid Environments. 2011; https://doi.org/10.1016/j.jaridenv.2011.05.011

6. Vincent V, Thomas R. An agricultural survey of Southern Rhodesia Part 1. Agro-ecological survey. Rhodesia Government Printers, 1960.

7. Manatsa D, Mushore TD, Gwitira I, Wuta M, Chemura A, Shekede MD, Mugandani R, Sakala LC, Ali LH, Mupuro J, Muzira NM. Revision of Zimbabwe's agro-ecological zones. Produced by the Government of Zimbabwe under Zimbabwe National Geospatial and Space Agency (ZINGSA) for the Ministry of Higher and Tertiary Education, Innovation, Science and Technology Development. Zimbabwe Government Printers (In Press), 2020.

8. Rockström J, Barron J, Fox P. Water Productivity in Rain-fed Agriculture: Challenges and Opportunities for Smallholder Farmers in Drought prone Tropical Agroecosystems. In: Kijne WJ, Barker R, Molden D, editors. Water productivity in Agriculture: Limits and Opportunities for Improvement. Wallingford: CAB International; 2003. pp. 145-162.

9. Barron J, Rockström J, Gichuki F, Hatibu N. Dry spell analysis and maize yields for two semi-arid locations in East Africa. Agricultural and Forest Meteorology. 2003; 117:23-37.

10. Rurinda J, Mapfumo P, vam Wijk MT, Mtambanengwe F, Rufino MC, Chikowo R, Giller KE. Comparative assessment of productivity of maize, finger millet and sorghum for household food security in the face of increasing climatic risk. European Journal of Agronomy. 2014; 55:29-41.

11. Zimbabwe Vulnerability Assessment Committee (ZIMVAC). Rural Livelihoods Assessment Report. Scientific Industrial Research and Development Centre (SIRDC) - Food and Nutrition Council (FNC), 1574 Alpes Road, Hatcliffe, Harare, 2010.

12. Rockström J, Barron J. Water productivity in rainfed systems: Overview of challenges and analysis of opportunities in water scarcity prone savannahs. Irrigation Science. 2007; https://doi.org/10.1007/s00271-007-0062-3

13. Molden D, Oweis T, Pasquale S, Kijne J, Hanjira M, Bindraban P, Bouman B, Cook S, Erenstein O, Farahani H, Hachum A, Hoogeveen J, Mahoo H, Nangia V, Peden D, Sikka A, Silva P, Turral H, Upadhyaya A, Zwart S. Pathways for increasing agricultural water productivity. In: Molden D. editor. Water for Food, Water for Life: A Comprehensive Assessment of Water Management in Agriculture. London: Earthscan; 2007. pp. 279-310.

14. Nyagumbo I, Munamati M, Chikwari E, Gumbo D. In-situ water harvesting technologies in semi-arid southern Zimbabwe: Part I. The role of biophysical factors on performance in Gwanda district. Paper 
presented at the 10th WaterNet/WARFSA/GWP-SA Annual Symposium, Entebbe, Uganda, 2009. Amsterdam, Netherlands: WaterNet; 2009.

15. Nyakudya IW, Stroosnijder L. Water management options based on rainfall analysis for rainfed maize (Zea mays L.) production in Rushinga district, Zimbabwe. Agricultural Water Management. 2011; https://doi.org/10.1016/j.agwat.2011.06.002

16. ITDG. Annual report 2003; 2004.

17. Alvord ED. Development of Native Agriculture and Land Tenure in Southern Rhodesia. Salisbury: Waddilove; 1958.

18. Aylen D. Who built the first contour ridges? The Rhodesia Agricultural Journal. 1941; 36:452-484.

19. Biazin B, Sterk G, Temesgen M, Abdulkedir A, Stroosnijder L. Rainwater harvesting and management in rainfed agricultural systems in sub-Saharan Africa - A review. Physics and Chemistry of the Earth. 2012; https://doi.org/10.1016/j.pce.2011.08.015

20. Falkenmark M, Rockström J. Balancing Water for Humans and Nature: The New Approach in Ecohdrology. London: Routledge; 2004.

21. Mupangwa W, Twomlow S, Walker $S$. The influence of conservation tillage methods on soil water regimes in semi-arid southern Zimbabwe. Physics and Chemistry of the Earth. 2008; https://doi.org/10.1016/j.pce.2008.06.049

22. Mupangwa W, Twomlow S, Walker S. Dead level contours and infiltration pits for risk mitigation in smallholder cropping systems of southern Zimbabwe. Physics and Chemistry of the Earth. 2012; https://doi.org/10.1016/j.pce.2011.06.011

23. Hagmann J, Chuma E, Murwira K, Connolly M. Putting process into practice: operationalising participatory extension. ODI Agricultural Research and Extension. 1999; 94:1-24.

24. Masendeke A, Mlalazi A, Ndlovu A, Gumbo D. (2004). Empowering communities through CBP in Zimbabwe: Experiences in Gwanda and Chimanimani. IIED PLA Notes. 2004; 49:44-49.

25. Scoones I. Livestock Populations and the Household Economy: A Case Study from Southern Zimbabwe. London: Imperial College; 1990.

26. Spielman DJ, Ekboir J, Davis K. The art and science of innovation systems inquiry: Applications to Sub-Saharan African agriculture. Technology in Society. 2009; https://doi.org/10.1016/j.techsoc.2009.10.004

27. Steinke J, Etten J, Zelan P. The accuracy of farmer-generated data in an agricultural citizen science methodology. Agronomy for Sustainable Development. 2017; 37:32-38.

28. Thompson, L., Gelwen, K., Elmore, R., Rees, J., Pokal, S., \& Hitt, BFarmers as Researchers: In-depth Interviews to discern Participant Motivation and Impact. Agronomy Journal. 2019; 111(6): 26702680.

29. Hoffmann, V., Probst, K., \& Christinck, A. Farmers and researchers: How can collaborative advantages be created in participatory research and technology development? Agriculture and Human Values. 2007; 24: 355-368. 
30. Pretty J. Farmers' Extension Practice and Technology Adaptation: Agricultural Revolution in 17-19th Century Britain. Agricultural Human Values; 1991: 8: 132-148.

31. Farrington, J., and Martin, A. M. Farmer participatory research: A review of concepts and recent fieldwork. Agricultural Administration and Extension. 1988; 29 (4): 247-264.

32. Masuka, B., Atlin, G.N., Olsen, M., Magorokosho, C., Labuschagne, M., Crossa, J., Bänziger, M., Pixley, K.V., Vivek, B.S., von Biljon, A. Grains in genetic improvement in Eastern and Southern Africa: I. CIMMYT hybrid breeding pipeline. Crop Science. 2017: 57, 168-179.

33. Sud, U.C.; Ahmad, T.; Gupta, V.K.; Chandra, H.; Sahoo, P.M.; Aditya, K.; Singh, M.; Biswas, A. Global Strategy. In Synthesis of Literature and Framework-Research on Improving Methods for Estimating Crop Area, Yield and Production under Mixed, Repeated and Continuous Cropping, ICAR-Indian Agricultural Statistics Research Institute: New Delhi, India, 2016.

34. Evans, L.T.; Fischer, R.A. Yield potential: Its definition, measurement and significance. Crop Science. $1999 ; 39,1544-1551$.

35. Gomez A, Gomez A. Statistical Procedures for Agricultural Research. Hoboken: John Wiley \& Sons; 1984.

36. Mupangwa W, Twomlow S, Walker S. Rainwater harvesting using dead level contours and infiltration pits under semi-arid conditions in Zimbabwe. Paper presented at the 10th WaterNet/WARFSA/GWPSA Annual Symposium, Entebbe, Uganda, 2009. Amsterdam: WaterNet. 2009; https://cgspace.cgiar.org/handle/10568/21334

37. Hatibu N, Mahoo H. Rainwater harvesting technologies for agricultural production. In: Khaumbutho P, Simalenga T. editors. A resource book of the Animal Traction Network for Eastern and Southern Africa (ATNESA). Windhoek, Namibia: French Cooperation. 1999; http://www.atnesa.org

38. Nyagumbo I, Nyamadzawo G, Madembo C. Effects of three in-field water harvesting technologies on soil water content and maize yields in a semi-arid region of Zimbabwe. Agricultural Water Management. 2019; https://doi.org/10.1016/j.agwat.2019.02.02

39. Mutekwa V, Kusangaya S. Contribution of rainwater harvesting technologies to rural livelihoods in Zimbabwe: The case of Ngundu ward in Chivi District. Water SA. 2006; https://doi.org/10.4314/wsa.v32i3.5270

40. Ren B, Dong S, Zhao B, Liu P, Zhang J. Responses of nitrogen metabolism, uptake and translocation of maize to waterlogging at different growth stages. Frontiers in Plant Science. 2017; https://doi.org/10.3389/fpls.2017.01216

41. Mafongoya P, Rusinamhodzi L, Siziba S, Thierfelder C, Mvumi BM, Nhau B, Hove L, Chivenge P. Maize productivity and profitability in Conservation Agriculture systems across agro-ecological regions in Zimbabwe: A review of knowledge and practice. Agriculture, Ecosystems and Environment. 2016; https://doi.org/10.1016/j.agee.2016.01.017

42. Nyamangara J, Nyengerai K, Masvaya EN, Tirivavi R, Mashingaidze N, Mupangwa W, Dimes J, Hove $\mathrm{L}$, Twomlow S. Effect of conservation agriculture on maize yield in the semi-arid areas of Zimbabwe. Experimental Agriculture. 2014; https://doi.org/10.1017/S0014479713000562 
43. Mazvimavi K, Twomlow S. Socio-economic and institutional factors influencing adoption of conservation farming by vulnerable households in Zimbabwe. Agricultural Systems. 2009; https://doi.org/10.1016/j.agsy.2009.02.002

44. Griffith DR, Kladivko EJ, Mannering JV, West TD, Parsons SD. Long-term tillage and rotation effects on corn growth and yield on high and low organic matter, poorly drained soils. Agronomy Journal. 1988; 80:599-605

45. IPCC. Global Warming of $1.5^{\circ} \mathrm{C}$. An IPCC Special Report on the impacts of global warming of $1.5^{\circ} \mathrm{C}$ above pre-industrial levels and related global greenhouse gas emission pathways, in the context of strengthening the global response to the threat of climate change, sustainable development, and efforts to eradicate poverty [Masson-Delmotte, V., P. Zhai, H.-O. Pörtner, D. Roberts, J. Skea, P.R. Shukla, A. Pirani, W. Moufouma-Okia, C. Péan, R. Pidcock, S. Connors, J.B.R. Matthews, Y. Chen, X. Zhou, M.I. Gomis, E. Lonnoy, T. Maycock, M. Tignor, and T. Waterfield (eds.)]. 2018

46. Mugabe FT. Evaluation of the Benefits of Infiltration Pits on Soil Moisture in Semi-Arid Zimbabwe. Journal of Agronomy. 2004; 3(3):188-190.

47. Gumbo D, Snelder D, Wuta M, Nyagumbo I. Zimbabwe: Keeping runoff on the land. In: Critchley W, Gowing J. editors. Water Harvesting in Sub-Saharan Africa. London: Routledge. 2013; https://doi.org/10.4324/9780203109984

48. Kwashirai V. Dilemmas in Conservationism in Colonial Zimbabwe, 1890-1930. Conservation and Society 2006; https://www.jstor.org/stable/26392861

\section{Figures}




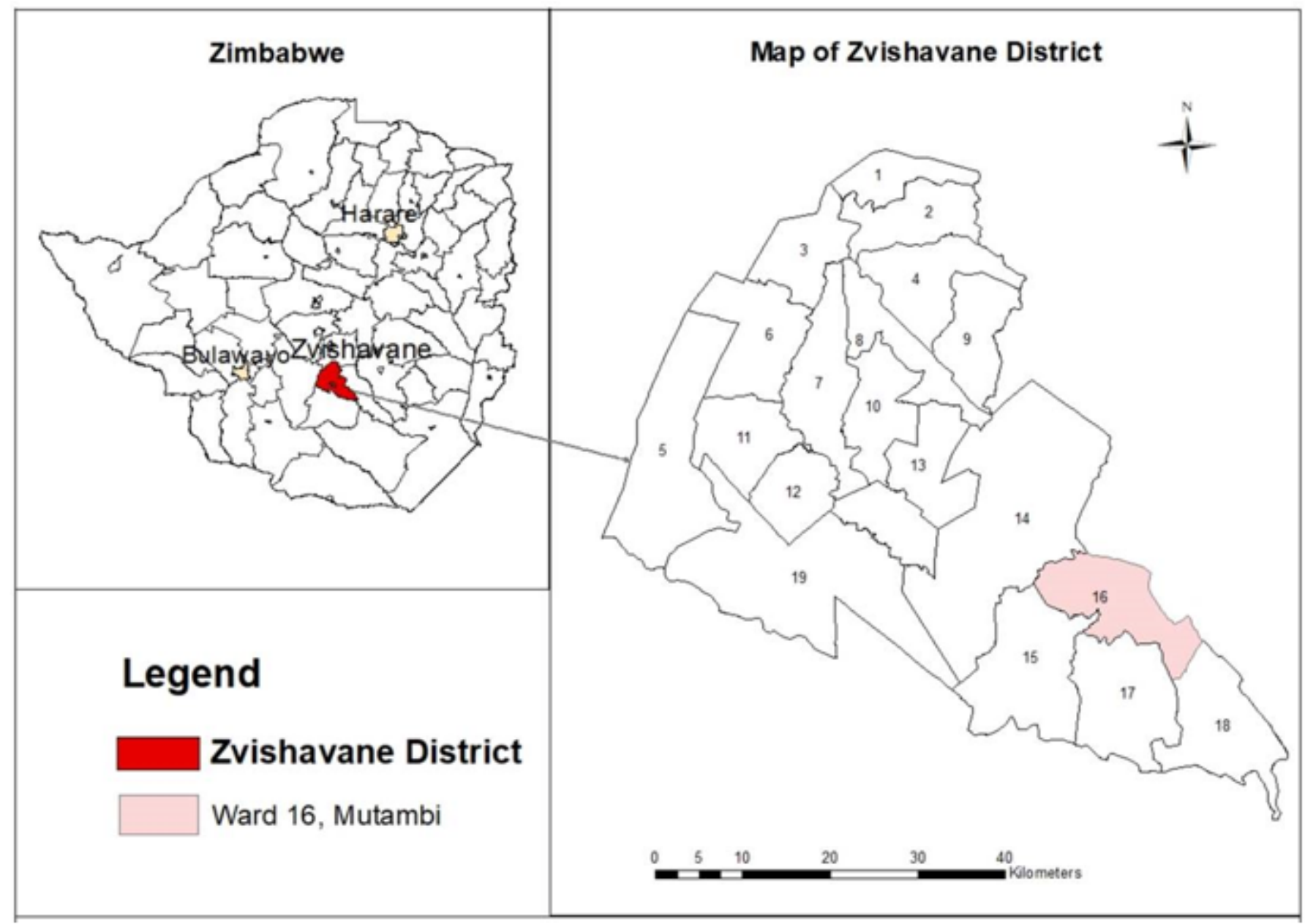

Figure 1

Location of the study area, Ward 16, Mutambi, Zvishavane District, Zimbabwe. Note: The designations employed and the presentation of the material on this map do not imply the expression of any opinion whatsoever on the part of Research Square concerning the legal status of any country, territory, city or area or of its authorities, or concerning the delimitation of its frontiers or boundaries. This map has been provided by the authors. 


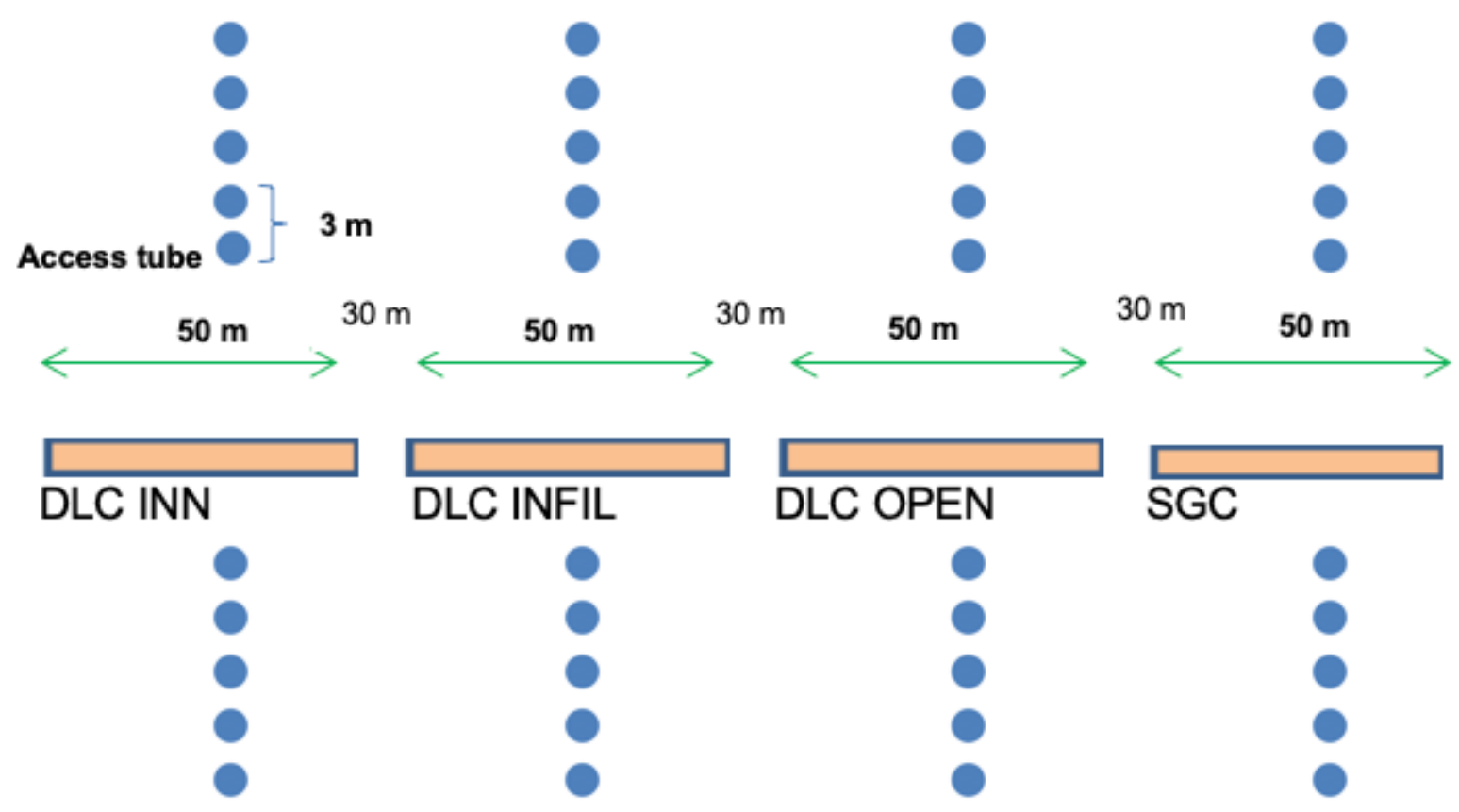

Figure 2

Position of access tubes upslope and downslope of technologies and distance between treatments at each farmer's field

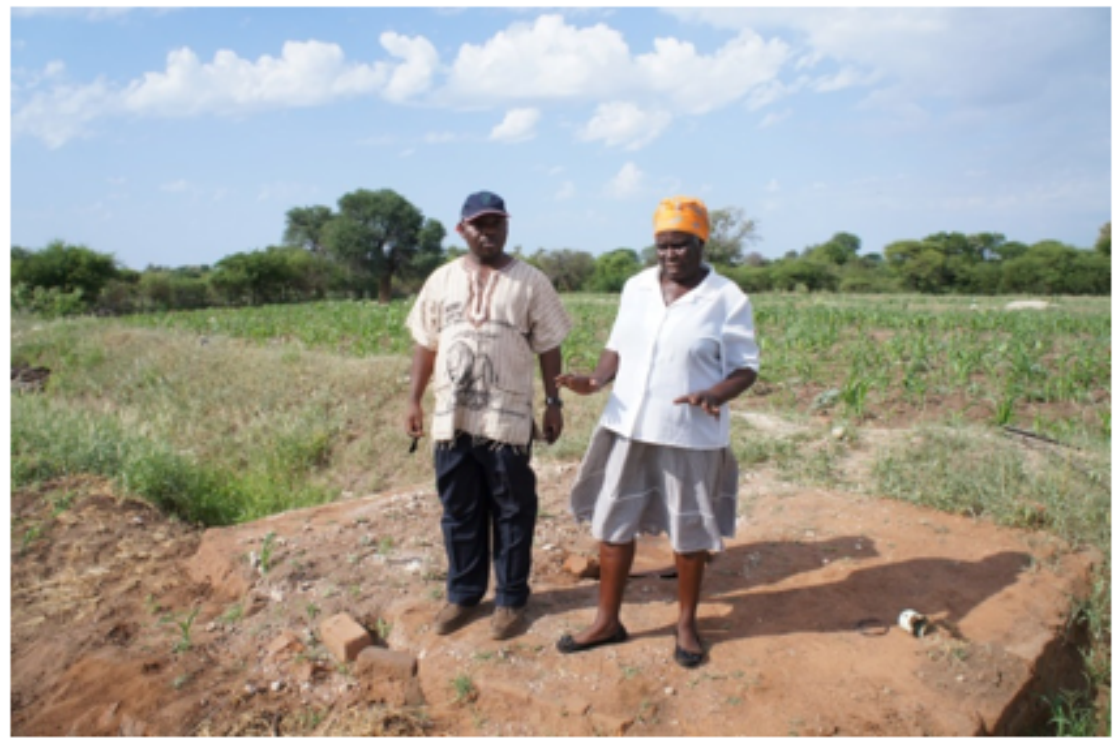

Figure 3

The infiltration pit covered on top to reduce the loss of water through evaporation 

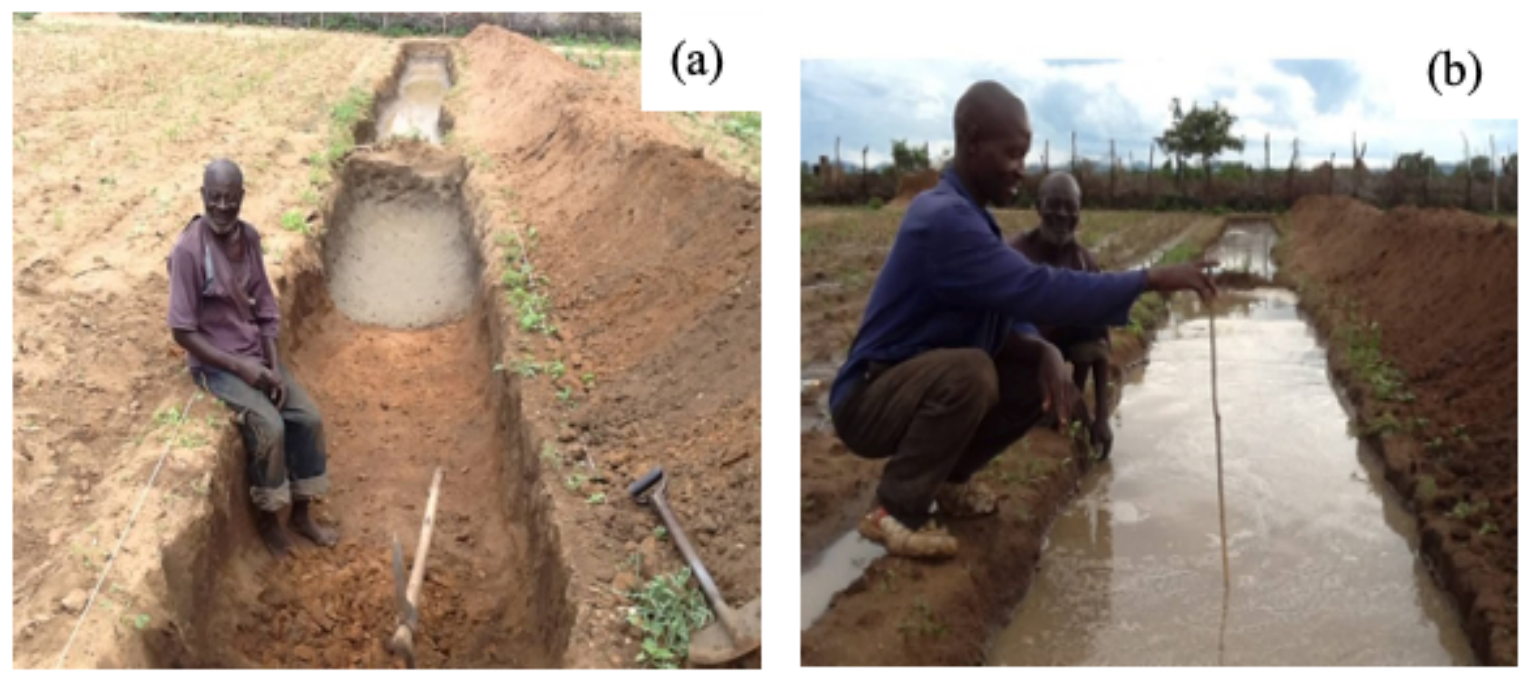

Figure 4

Water levels before (a) and after (b) a rainfall event on medium textured soils in Zvishavane 


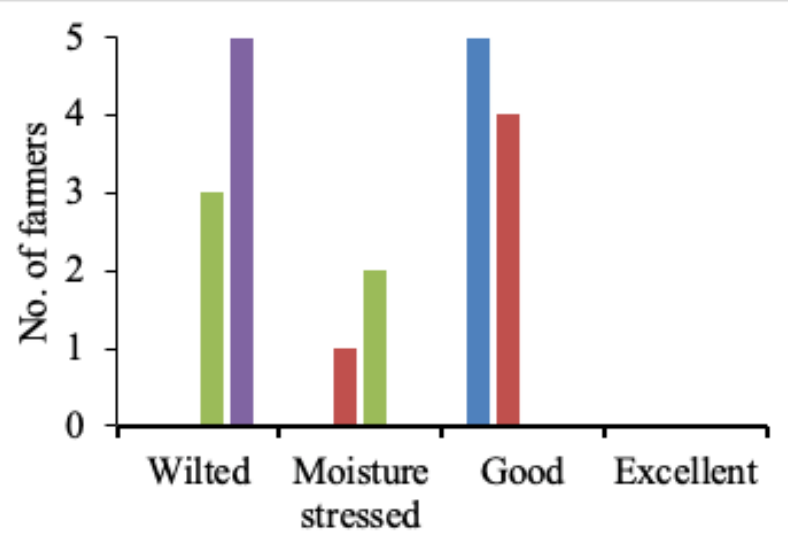

(a)

- DLC INN

$\because$ DLC INFIL

$\because$ DLC OPEN

- SGC

Crop condition on heavy textured soils

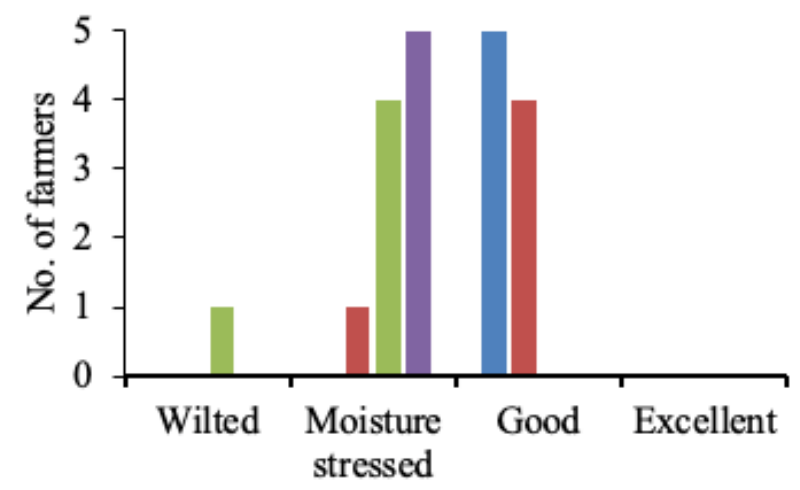

(b)

DLC INN

$\because$ DLC INFIL

$\because$ DLC OPEN

$=\mathrm{SGC}$

Crop condition on heavy textured soils

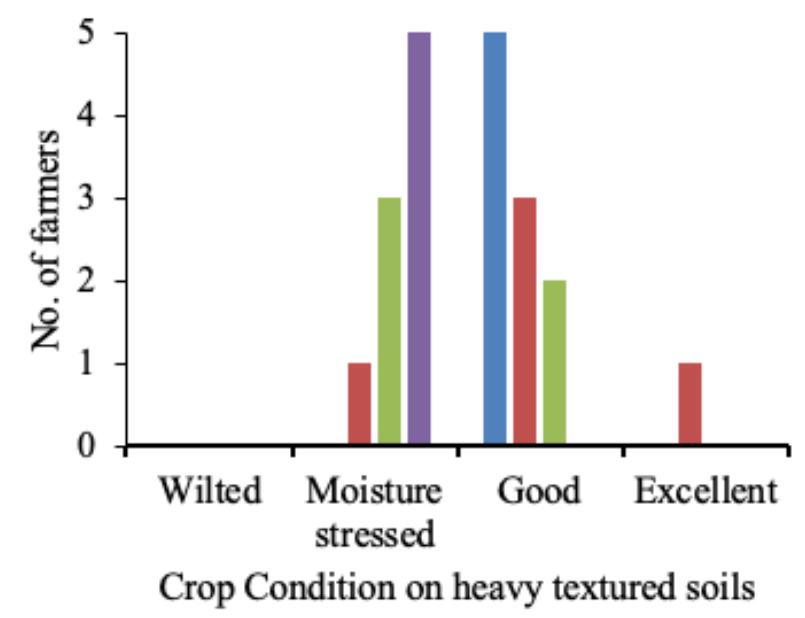

(c)

- DLC INN

- DLC INFIL

$\square$ DLC OPEN

- SGC

\section{Figure 5}

Farmer assessment of maize crop conditions on heavy textured soils during the flowering and silking stages of maize for the (a) 2011/12, (b) 2012/13 and (c) 2013/14 seasons in Zvishavane DistrictTwenty percent of the farmers used the DLC OPEN for the 2012/13 season, as shown in Figure $5 a$ and $5 b$. 

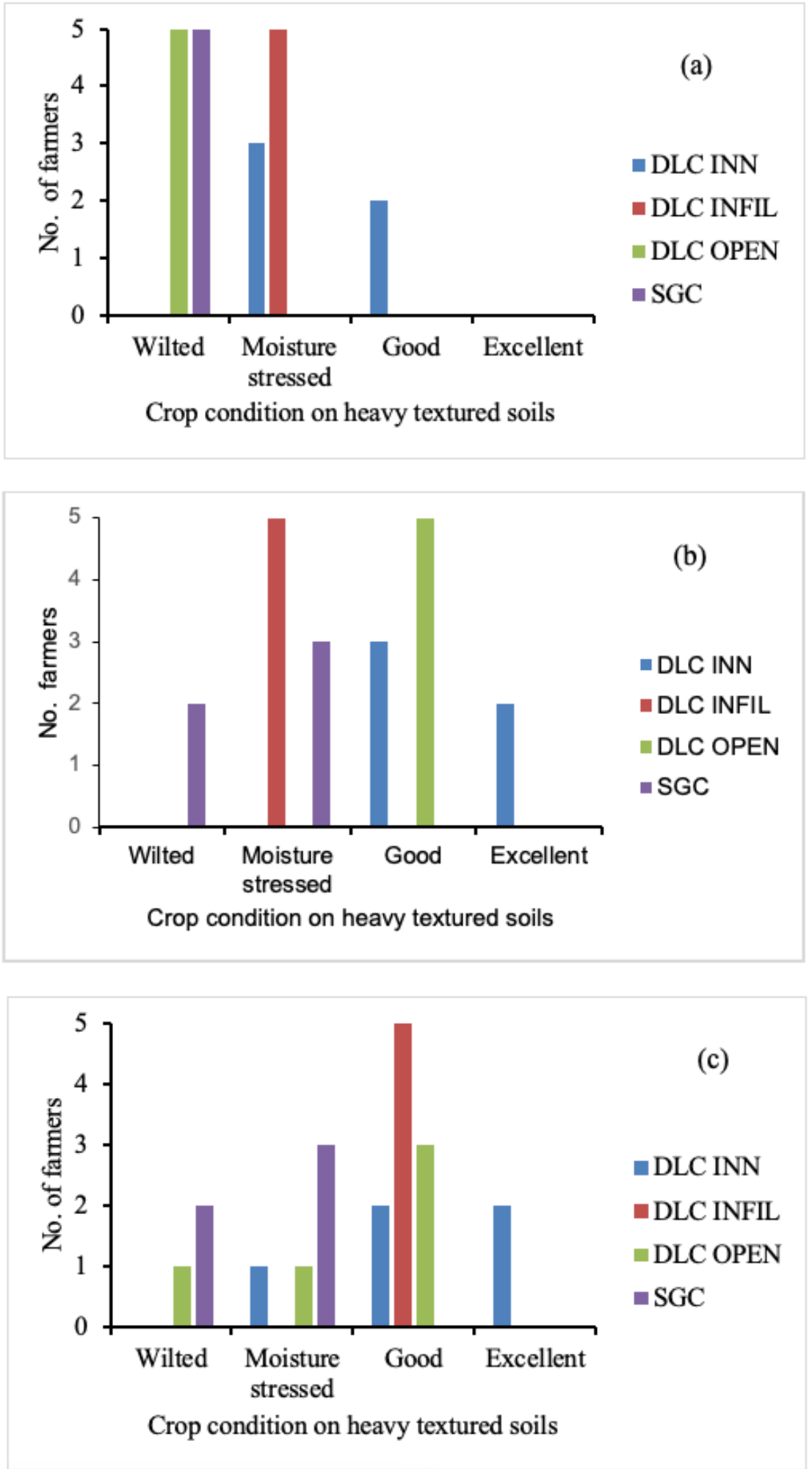

\section{Figure 6}

Farmer assessment of maize crop conditions on heavy textured soils during the grain filling stage of maize for the (a) 2011/12, (b) 2012/13 and (c) 2013/14 seasons in Zvishavane District 

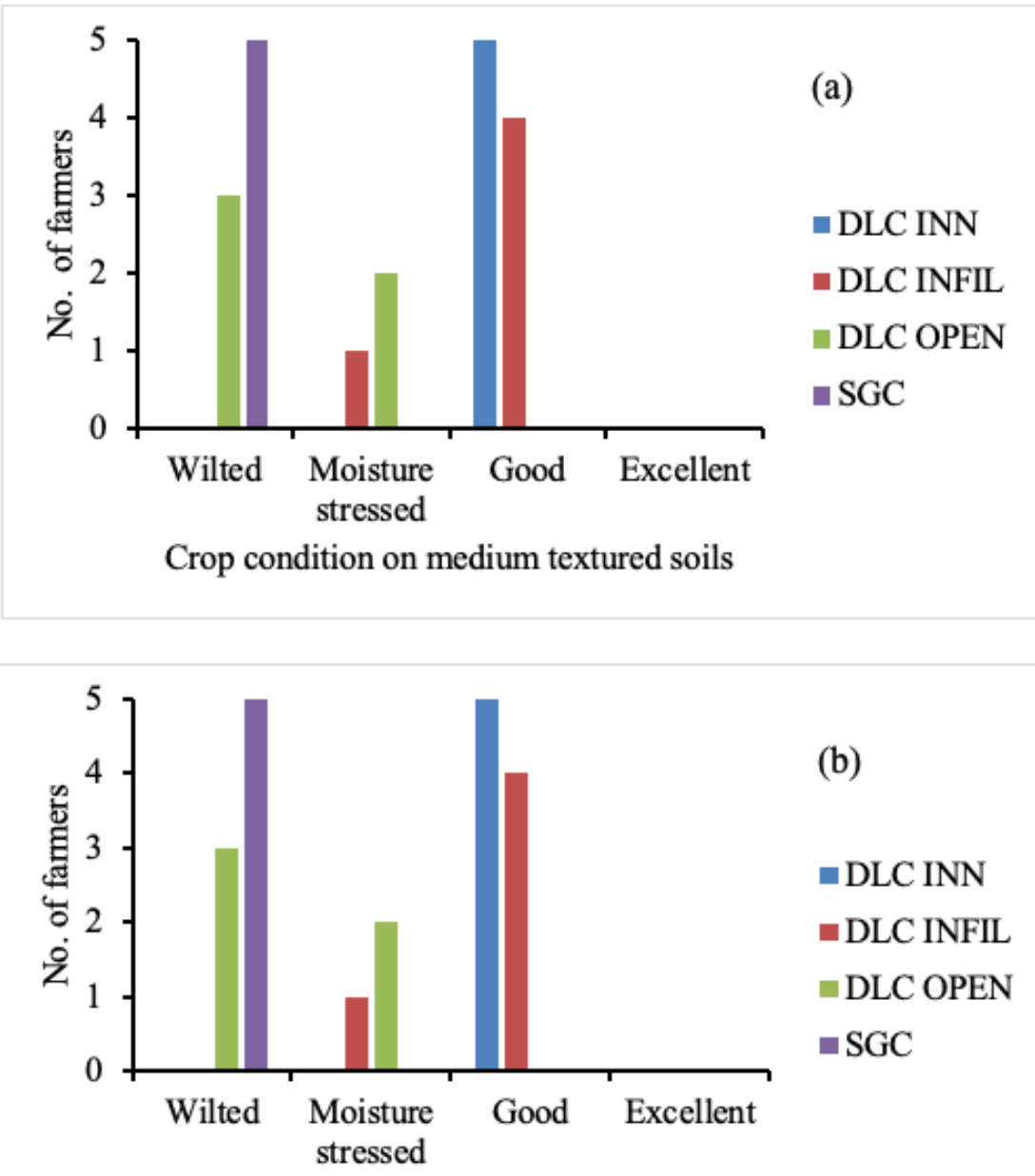

(b)

$\because$ DLC INN

- DLC INFIL

$\square$ DLC OPEN

- SGC

Crop condition on medium textured soils

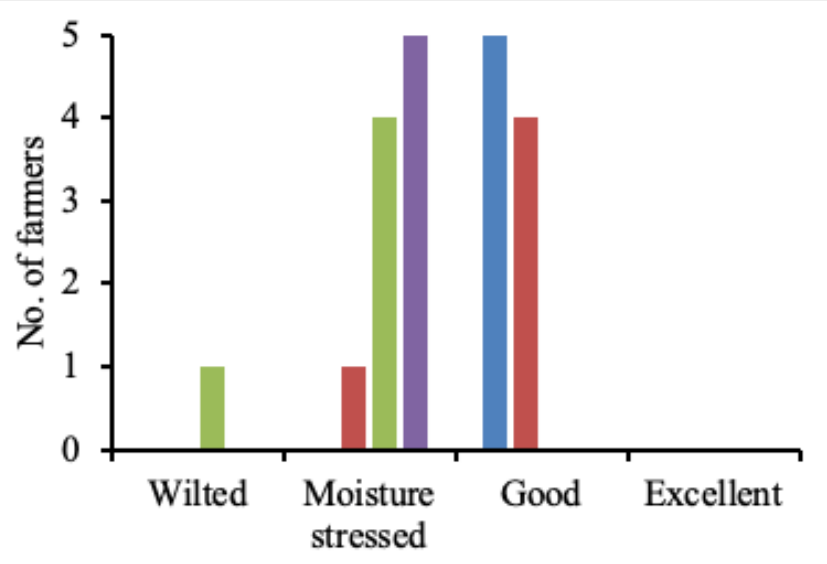

(c)

- DLC INN

DLC INFIL

DLC OPEN

-SGC

Crop condition on medium texured soils

\section{Figure 7}

Farmer assessment of maize crop conditions on medium textured soils during the flowering and silking stages of maize for the (a) 2011/12, (b) 2012/13 and (c) 2013/14 seasons in Zvishavane District 

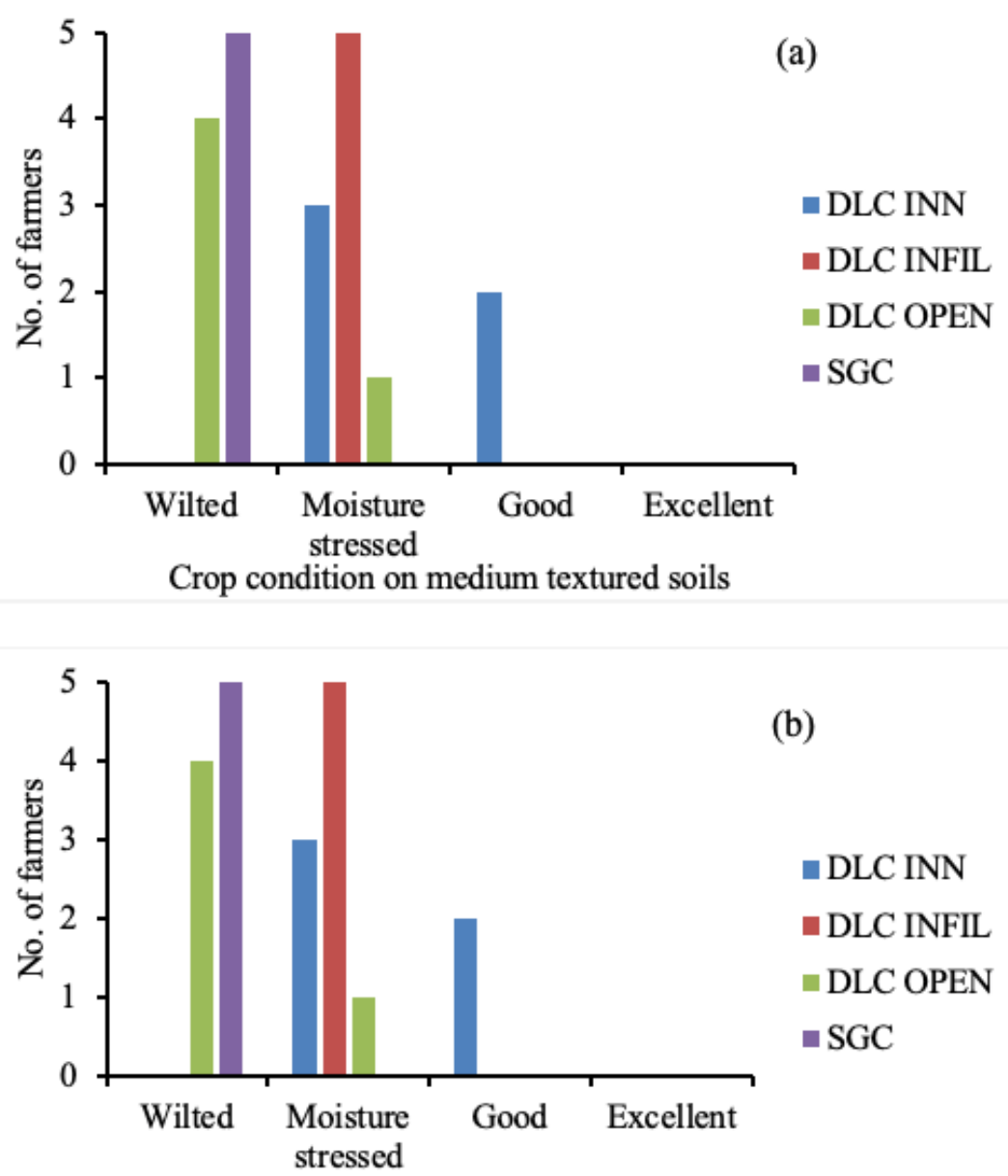

(b)

\section{- DLC INN}

DLC INFIL

DLC OPEN

- SGC

Crop condition on medium textured soils

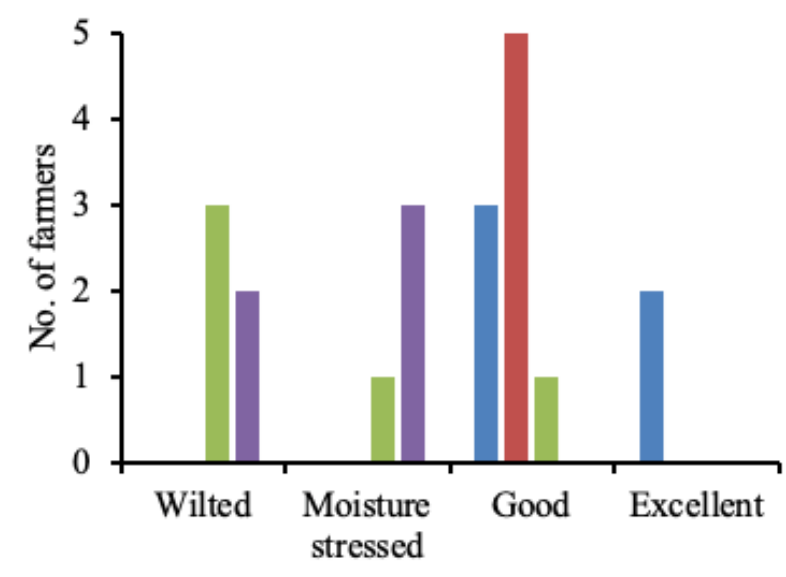

(c)

- DLC INN

口LC INFIL

DLC OPEN

$\because \mathrm{SGC}$

Crop condition on medium textured soils

\section{Figure 8}

Farmer assessment of maize crop conditions on medium textured soils during the grain filling stage of maize for (a) 2011/12, (b) 2012/13 and (c) 2013/14 in Zvishavane District. 


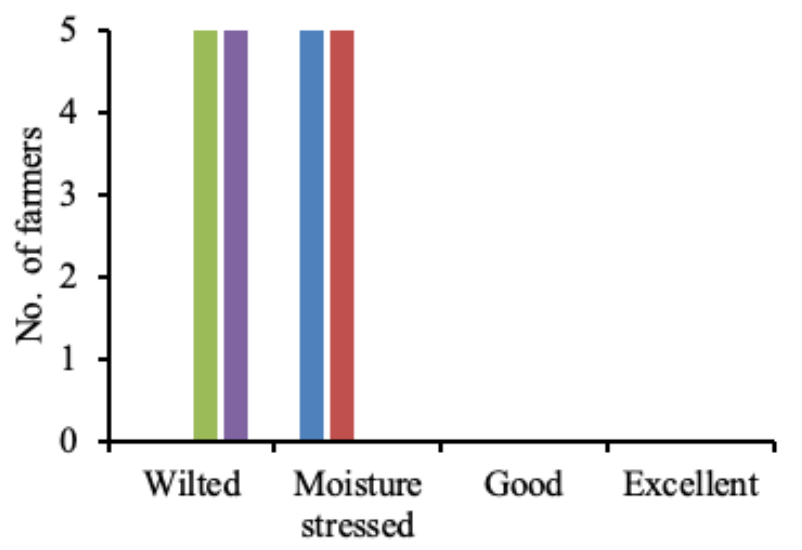

(a)

DLC INN

DLC INFIL

DLC OPEN

$\because \mathrm{SGC}$

Crop condition on light textured soils

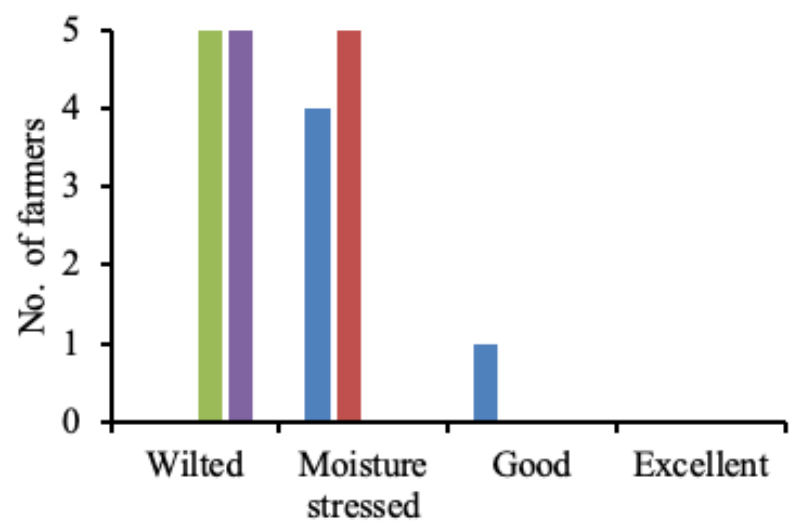

(b)

- DLC INN

- DLC INFIL

- DLC OPEN

- SGC

Crop condition on light textured soils

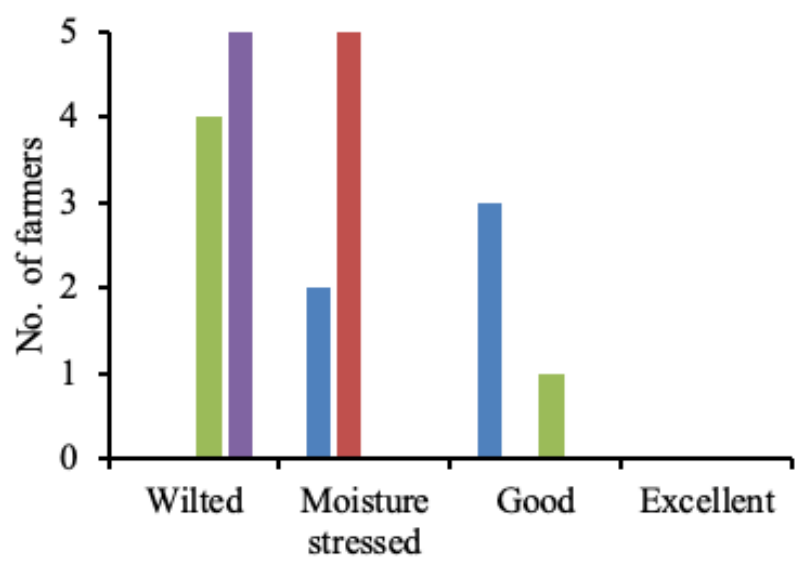

(c)

- DLC INN

- DLC INFIL

DLC OPEN

$\triangle \mathrm{SGC}$

Crop condition on light textured soils

\section{Figure 9}

Farmer assessment of maize crop conditions in light textured soils during the flowering and silking stages of maize for the (a) 2011/12, (b) 2012/13 and (c) 2013/14 seasons in Zvishavane. 

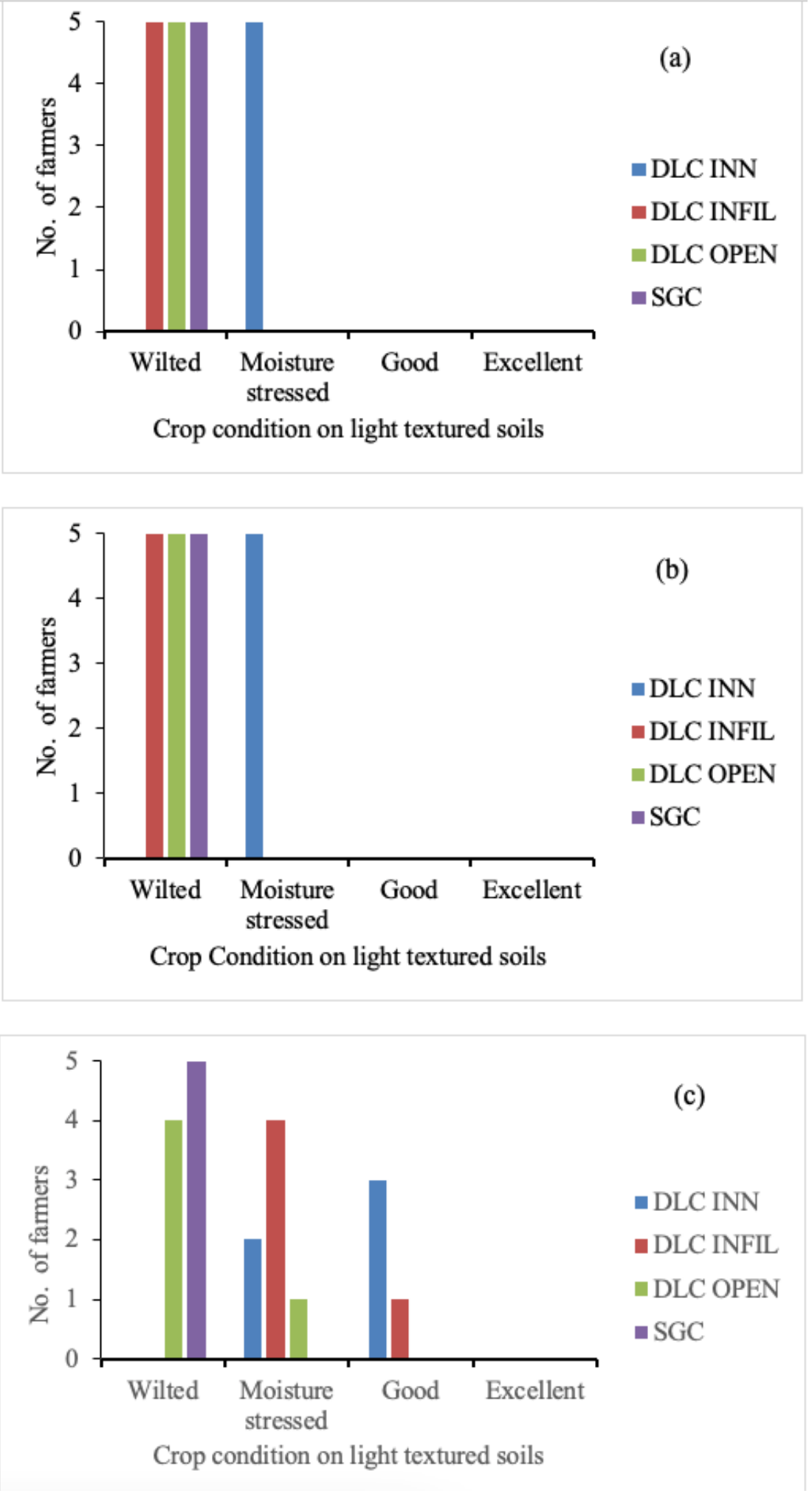

Figure 10

Farmer assessment of maize crop condition on light textured soils during the grain filling stage of maize for the (a) 2011/12, (b) 2012/13 and (c) 2013/14 seasons in Zvishavane District. 

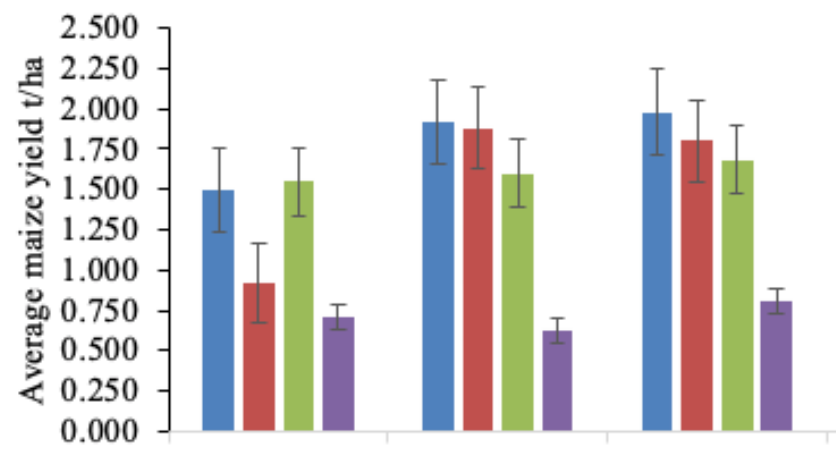

(a)

$(+) 0-3$

(+) 3-6

$(+) 6-9$

(+)9-12

$(+) 12-15$

Distance from technology channel $(\mathrm{m})$

$\square$ DLC INN $\quad$ DLC INFIL $\approx$ DLC open $\quad \square$ SGC

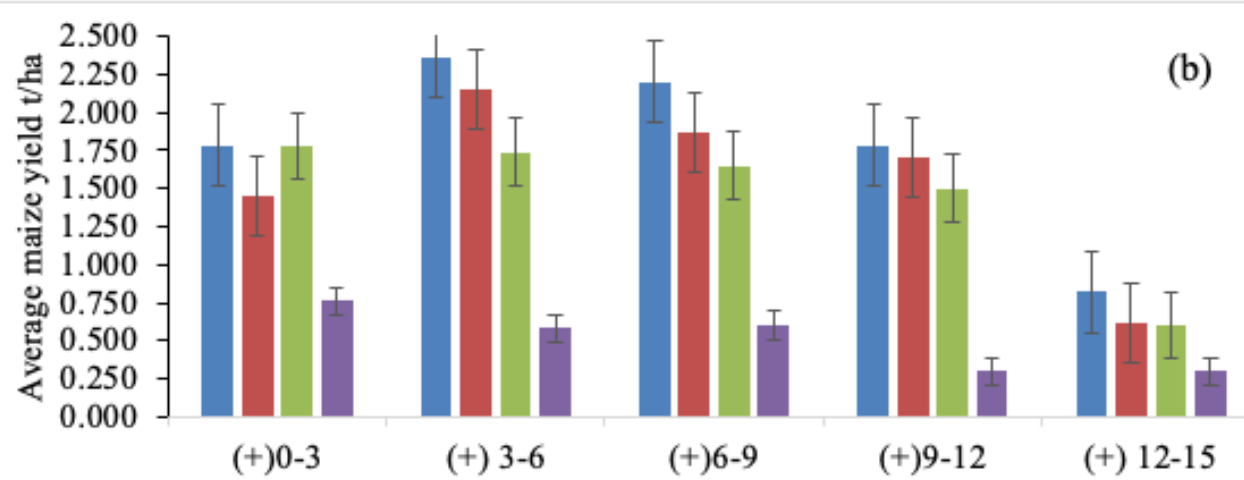

Distance from technology channel (m)

$\approx$ DLC INN $=$ DLC INFIL $\quad$ DLC open $\quad \|$ SGC

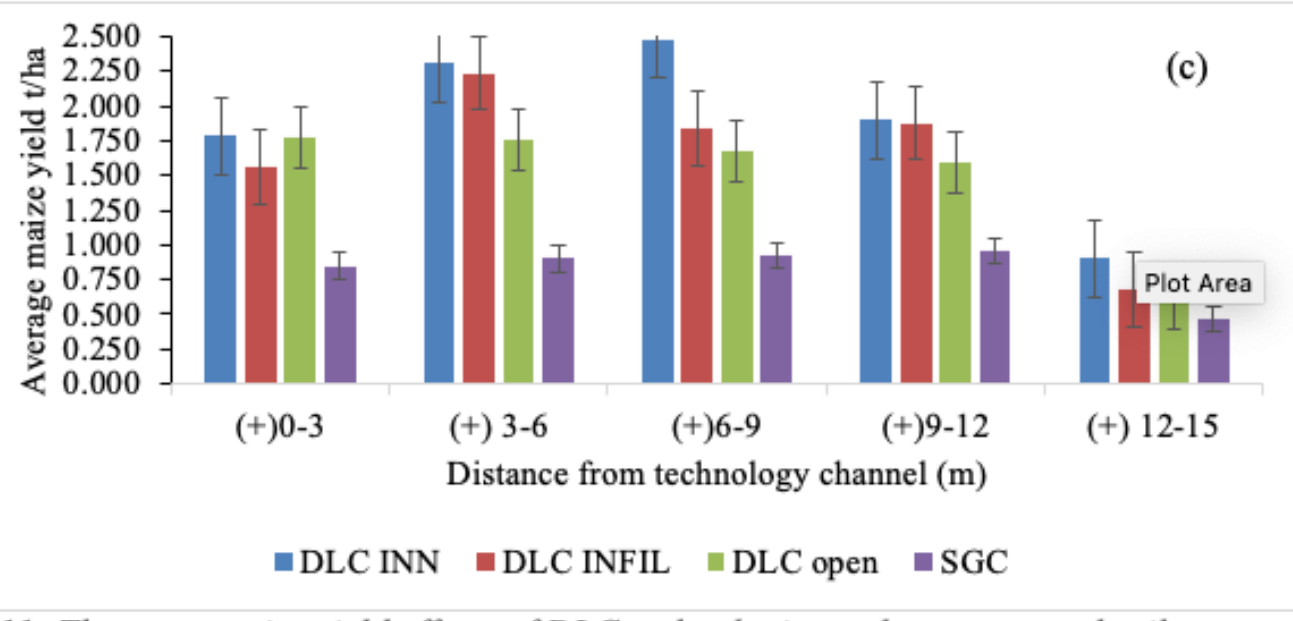

\section{Figure 11}

The mean maize yield effects of DLC technologies on heavy textured soils up (+) slope from the technology channel for the (a) 2011/12 (b) 2012/13 (c) 2013/14 season in Zvishavane District. Vertical bar $=$ standard error (SE). 


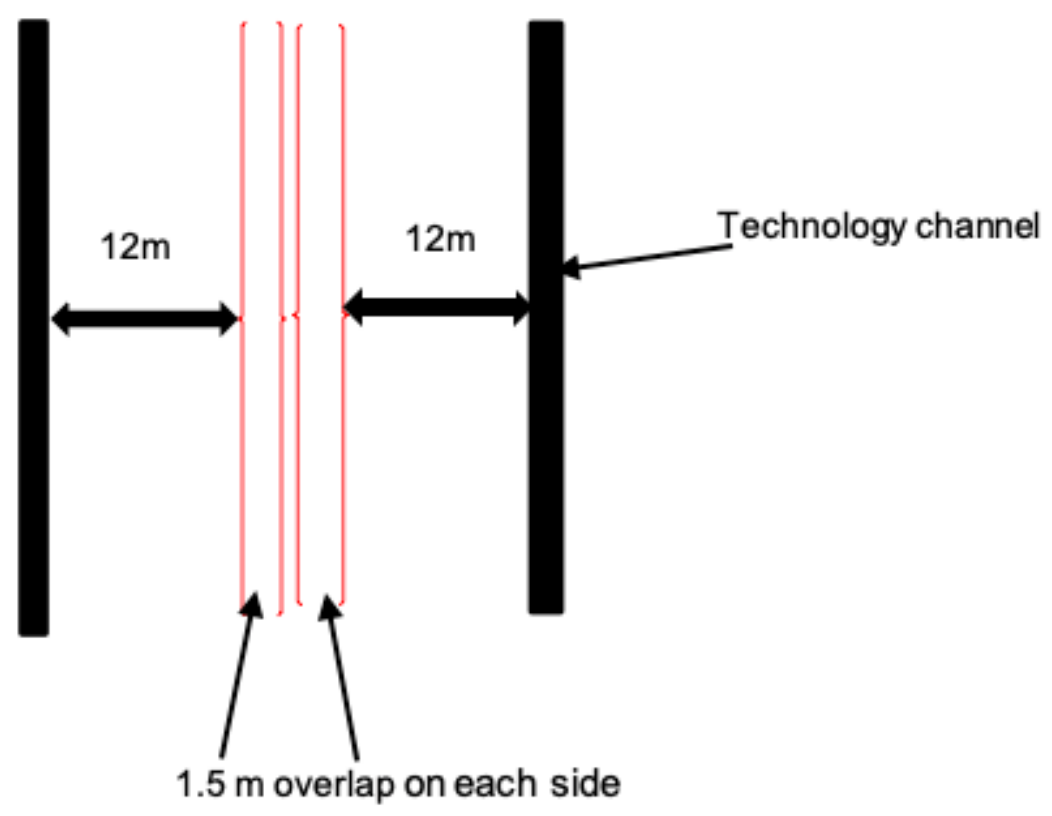

Figure 12

Ilustration of the layout and spacing of DLC technology on heavy textured soils The effects of DLC technologies on maize yield in medium-textured soils 

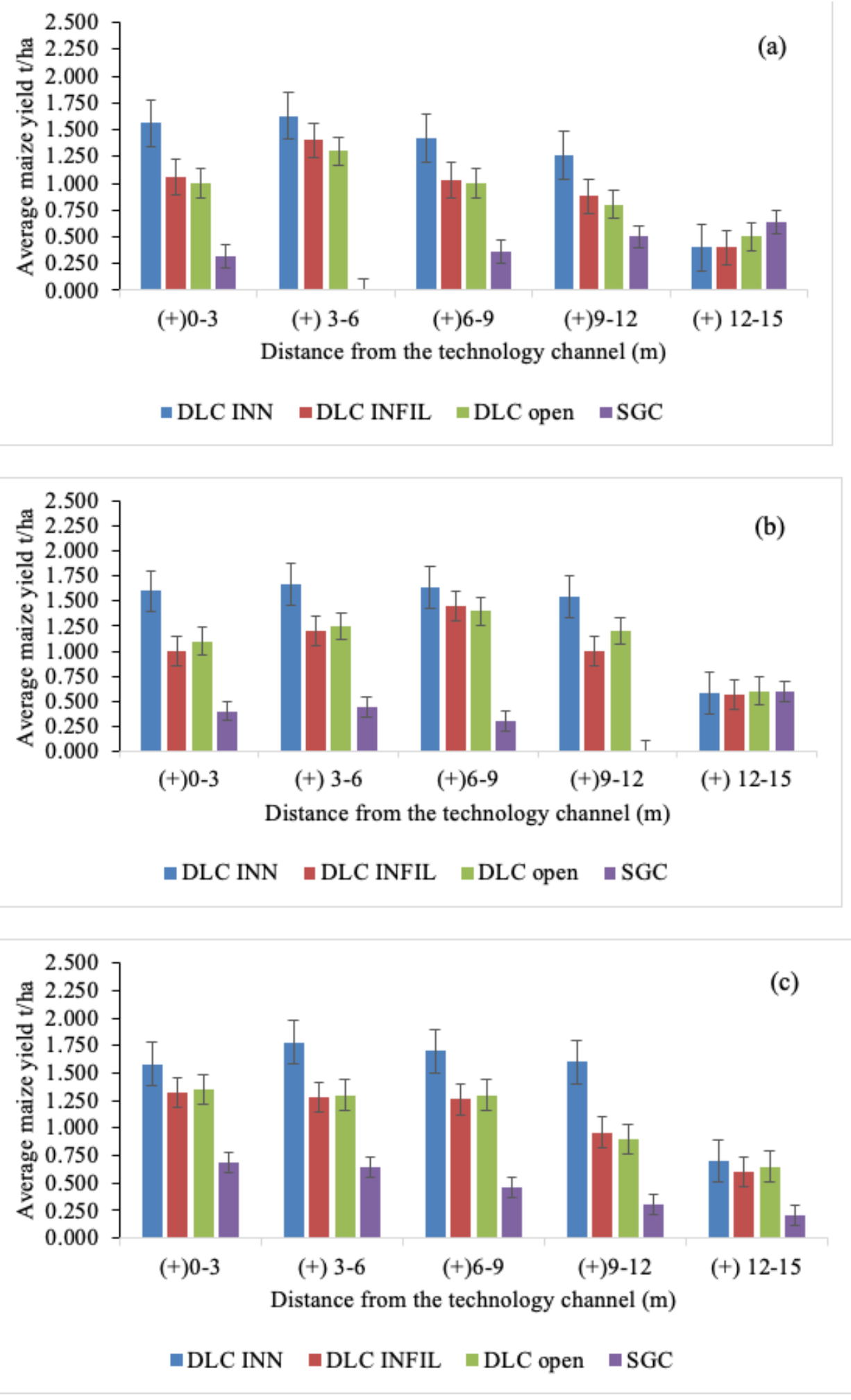

\section{Figure 13}

The mean maize yield effects of DLC technologies on medium textured soils up (+) slope from the technology channel for (a) 2011/12, (b) 2012/13, and (c) 2013/14 season in Zvishavane District. Vertical bar =standard error (SE). 

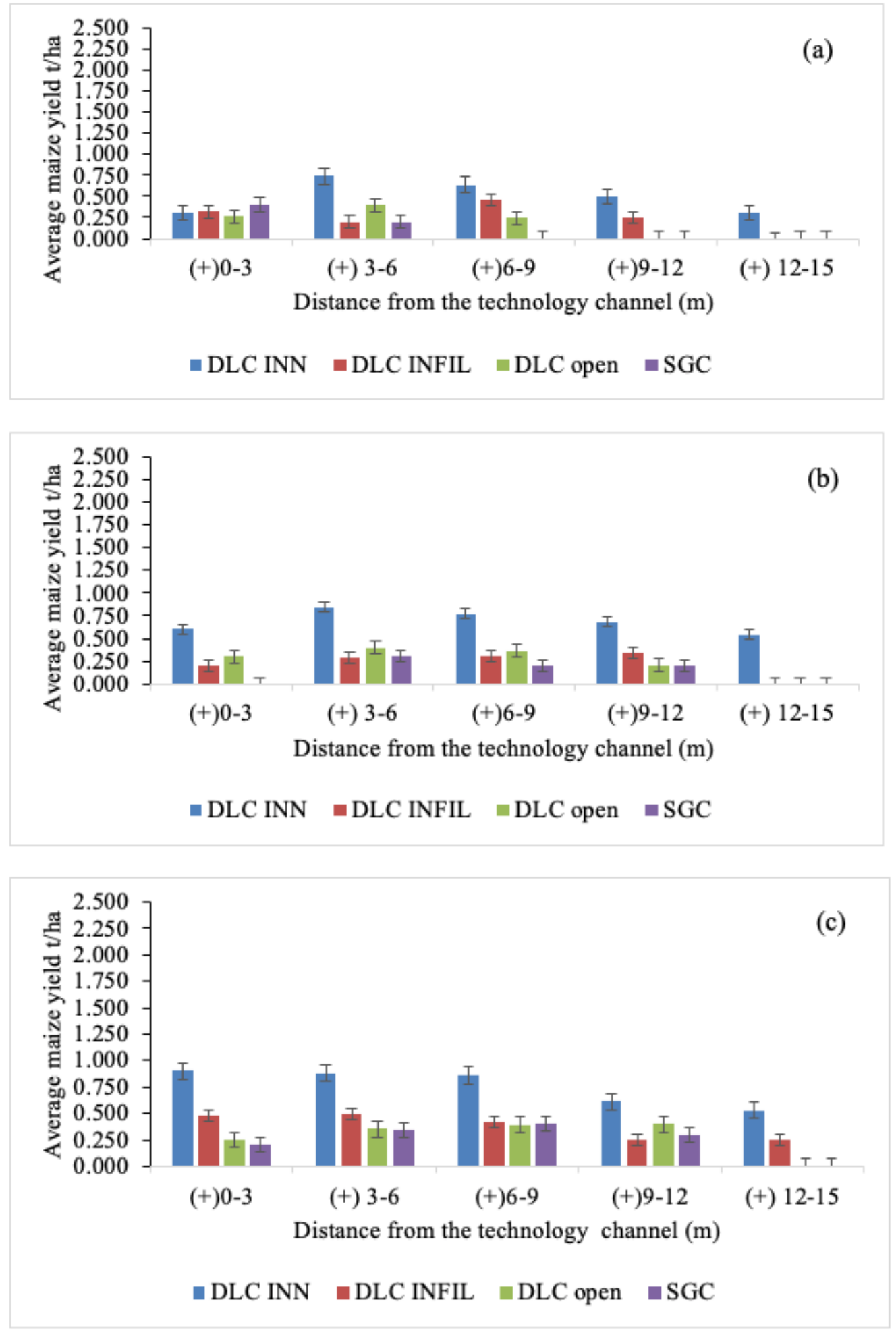

\section{Figure 14}

The mean maize yield effects of DLC technologies on light textured soils up (+) the slope from the technology channel for the (a) 2011/12, (b) 2012/13, and (c) 2013/14 seasons in Zvishavane District. Vertical bar $=$ standard error (SE). 